\title{
The Passive microwave Neural network Precipitation Retrieval (PNPR) algorithm for AMSU/MHS observations: description and application to European case studies
}

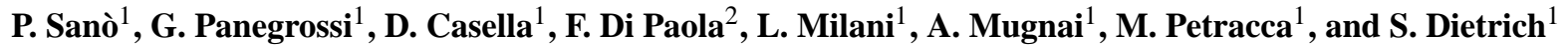 \\ ${ }^{1}$ Institute of Atmospheric Sciences and Climate (ISAC), Italian National Research Council (CNR), 00133 Rome, Italy \\ ${ }^{2}$ Institute of Methodologies for Environmental Analysis (IMAA), Italian National Research Council (CNR), C.da S.Loja, \\ Tito Scalo, 85050 Potenza, Italy
}

Correspondence to: P. Sanò (paolo.sano@artov.isac.cnr.it)

Received: 3 August 2014 - Published in Atmos. Meas. Tech. Discuss.: 15 September 2014

Revised: 20 January 2015 - Accepted: 22 January 2015 - Published: 19 February 2015

\begin{abstract}
The purpose of this study is to describe a new algorithm based on a neural network approach (Passive microwave Neural network Precipitation Retrieval - PNPR) for precipitation rate estimation from AMSU/MHS observations, and to provide examples of its performance for specific case studies over the European/Mediterranean area. The algorithm optimally exploits the different characteristics of Advanced Microwave Sounding Unit-A (AMSU-A) and the Microwave Humidity Sounder (MHS) channels, and their combinations, including the brightness temperature (TB) differences of the 183.31 channels, with the goal of having a single neural network for different types of background surfaces (vegetated land, snow-covered surface, coast and ocean). The training of the neural network is based on the use of a cloudradiation database, built from cloud-resolving model simulations coupled to a radiative transfer model, representative of the European and Mediterranean Basin precipitation climatology. The algorithm provides also the phase of the precipitation and a pixel-based confidence index for the evaluation of the reliability of the retrieval.

Applied to different weather conditions in Europe, the algorithm shows good performance both in the identification of precipitation areas and in the retrieval of precipitation, which is particularly valuable over the extremely variable environmental and meteorological conditions of the region.

The PNPR is particularly efficient in (1) screening and retrieval of precipitation over different background surfaces; (2) identification and retrieval of heavy rain for convective events; and (3) identification of precipitation over a cold/iced
\end{abstract}

background, with increased uncertainties affecting light precipitation. In this paper, examples of good agreement of precipitation pattern and intensity with ground-based data (radar and rain gauges) are provided for four different case studies. The algorithm has been developed in order to be easily tailored to new radiometers as they become available (such as the cross-track scanning Suomi National Polar-orbiting Partnership (NPP) Advanced Technology Microwave Sounder (ATMS)), and it is suitable for operational use as it is computationally very efficient. PNPR has been recently extended for applications to the regions of Africa and the South Atlantic, and an extended validation over these regions (using $2 \mathrm{yr}$ of data acquired by the Tropical Rainfall Measuring Mission precipitation radar for comparison) is the subject of a paper in preparation. The PNPR is currently used operationally within the EUMETSAT Hydrology Satellite Application Facility (H-SAF) to provide instantaneous precipitation from passive microwave cross-track scanning radiometers. It undergoes routinely thorough extensive validation over Europe carried out by the H-SAF Precipitation Products Validation Team.

\section{Introduction}

Clouds and precipitation play a very important role in the global water and energy cycle. Accurate global measurements of precipitation are therefore important for the validation of global climate models and for understanding the 
natural variability of the earth's climate. Moreover, rainfall monitoring can serve as an important element for risk management of severe precipitation events.

Space-borne monitoring of clouds and precipitation all around the globe has been gaining a growing interest from the international scientific community as a primary contribution to determine and detect the global climatic changes. Both infrared (IR) and microwave (MW) emissions are used for precipitation retrievals. While IR estimates of rainfall are only indirect because IR measurements are sensitive only to the uppermost layers of clouds, MW observations have the great advantage of providing a more direct measurement of the precipitation due to the ability of MW radiation to penetrate precipitating clouds and interact with its liquid and ice hydrometeors (e.g., Mugnai et al., 1990; Wilheit et al., 1994; Weng and Grody, 2000; Bennartz and Petty, 2001; Bauer et al., 2005). Passive microwave (PMW) techniques for the estimation of precipitation have seen great advances over the past years, due largely to the increased number of radiometers available, with improved sensing capabilities (i.e., higher spatial resolution, number of available channels useful for precipitation retrieval) and due to the several theoretical studies on microwave radiative transfer modeling through precipitating clouds (e.g., Mugnai et al., 1993; Wilheit et al., 1994; Smith et al., 1998, 2002; Stephens and Kummerow, 2007; Skofronick-Jackson and Johnson, 2011).

Satellite PMW observations are provided by radiometers aboard low Earth-orbiting (LEO) satellites, whose constellation has recently reached its optimal configuration for precipitation monitoring with the launch of the NASA/JAXA Global Precipitation Measurement (GPM) core satellite on 27 February 2014 (Hou et al., 2014), to provide 3-hourly global coverage of the precipitation between $65^{\circ} \mathrm{S}$ and $65^{\circ} \mathrm{N}$. PMW radiometers are usually categorized based on their scanning mode: (1) cross-polarized conical scanning configuration, such as the Special Sensor Microwave Imager/Sounder (SSMIS) aboard the Defence Meteorological Satellite Program satellites, the passive Tropical Rainfall Measuring Mission (TRMM) Microwave Imager (TMI) aboard the NASA TRMM satellite, and the advanced GPM Microwave Imager (GMI); (2) cross-track scanning configuration, such as the Advanced Microwave Sounding UnitA (AMSU-A) and the Microwave Humidity Sounder (MHS) aboard NOAA-18 and NOAA-19 and the ESA MetOp-A and MetOp-B satellites (which has replaced AMSU-B aboard previous NOAA satellites), and the Advanced Technology Microwave Sounder (ATMS) aboard the Suomi National Polar-orbiting Partnership (Suomi NPP).

Several precipitation retrieval algorithms have been developed throughout the years to exploit imaging and sensing capabilities of PMW radiometers of both types (e.g., Wilheit et al., 1994; Marzano et al., 1999; Kummerow et al., 2001; Mugnai et al., 2001; Stephens and Kummerow, 2007). This paper focuses on the AMSU-A and MHS radiometers originally designed for temperature and water va- por sounding, respectively. AMSU-A has 15 channels: 12 channels in the $54 \mathrm{GHz}$ oxygen band for temperature sounding, and three additional window channels at 23.8, 31.4, and $89 \mathrm{GHz}$. MHS (and AMSU-B), designed for humidity sounding, has five channels: three channels in the $183 \mathrm{GHz}$ water vapor absorption line, and two window channels at 89 and $150 \mathrm{GHz}$. It is worth noting that similar sets of channel frequencies are used in most PMW radiometers currently available, such as the conical scanning SSMIS radiometers and the cross-track ATMS. It is worth mentioning, however, that polarization $(\mathrm{V} / \mathrm{H})$ information from conical scanning instruments provides useful information for surface characterization, screening of not-precipitating area, and precipitation retrieval, which is not available from the mixed polarization signal of cross-track scanning radiometers. The effects of cloud and precipitation on microwave radiances of the AMSU/MHS channels have been extensively analyzed (Wang et al., 1989, 1997; Burns et al., 1997; Grody et al., 2000; Staelin and Chen, 2000; Greenwald and Christopher, 2002; Bennartz and Bauer, 2003; Hong et al., 2005; Deeter and Vivekanandan, 2005; Funatsu et al., 2007). Window channels are used for the retrieval of surface precipitation and other surface hydrological products. The retrieval of surface precipitation using low-frequency window channels is based on the contrast between surface and precipitation (for example over ocean) (Chen and Staelin, 2003). High-frequency channels at 89 and $150 \mathrm{GHz}$ are mostly affected by the scattering by ice and are useful in delineating precipitation due to the correlation between the upper portion of the clouds and surface rain rate (Weng and Grody, 2000; Weng et al., 2003). Specifically, the $150 \mathrm{GHz}$ channel is sensitive to smaller-sized ice particles due to its shorter wavelength relative to $89 \mathrm{GHz}$, and this improves the identification of precipitation area, especially in stratiform rain regimes (Ferraro et al., 2000; Bennartz and Bauer, 2003). However, there are large uncertainties related to the scattering signal due to unresolved microphysical issues. Recent publications (e.g, Skofronick-Jackson et al., 2013; Johnson et al., 2012; Kulie et al., 2010) have highlighted this issue and the need to further understand how different combinations of microphysical features affect high-frequency brightness temperatures. For this reason, the precipitation retrieval exploiting high frequencies is complicated by their sensitivity to the highly variable microphysical characteristics of iced hydrometeors (shape, size and density). This issue has of course a significant impact on light rain and snowfall retrieval. In PNPR this issue is tackled through continuous improvements and refinement of the microphysical parameterization in the cloud-radiation database used in the training phase of the neural network (NN).

Opaque channels (bands around 54 and $183 \mathrm{GHz}$ ) were originally designed to retrieve temperature and water vapor profiles due to their different sensitivity to specific layers of the atmosphere (Staelin and Chen, 2000; Blackwell and Chen, 2005). However the $183.31 \mathrm{GHz}$ absorption band 
channels have shown great potentials for precipitating cloud characterization and for precipitation retrieval. Due to the different penetration ability of radiation at microwave frequencies, low-level clouds have little effect on channels near the $183 \mathrm{GHz}$ water vapor band if the sounded atmospheric layers (as characterized by the water vapor weighting functions) are above the cloud top. On the other hand, high-level clouds lower the brightness temperatures (TBs) due both to the increased absorption by water vapor within the saturated cloud and to the scattering by ice and water droplets (Burns et al., 1997). Moreover, in the $183 \mathrm{GHz}$ water vapor absorption band, the TB depression increases as the frequency moves away from the center of the absorption band. As a matter of fact, the radiation at $183.31 \pm 7 \mathrm{GHz}$ can penetrate deeper into the cloud than for the other two $183 \mathrm{GHz}$ channels, and therefore it is subject to larger scattering from mid- and low cloud layers; the $183.31 \pm 1 \mathrm{GHz}$ channel primarily responds to deep convection with large, high-density ice particles into the upper atmosphere (Ferraro, 2004; Bennartz and Bauer, 2003, Hong et al., 2005; Burns et al., 1997; Funatsu et al., 2007). These different responses of the three $183.31 \mathrm{GHz}$ channels suggested the possibility of analyzing the vertical distribution of hydrometeors (Hong et al., 2005; Burns et al., 1997; Wang et al., 1989, 1997). Burns et al. (1997) developed a screening criterion based on the difference $\Delta_{31}$ between measured TBs at $183.31 \pm 3$ and $183.31 \pm 1 \mathrm{GHz}$ to detect and exclude convective events. Hong et al. (2005) derived methods to detect deep convective clouds and convective overshooting using the TB differences $\Delta_{17}, \Delta_{13}, \Delta_{37}$ (corresponding respectively to the differences between the $183.31 \pm 1$ and $183.31 \pm 7 \mathrm{GHz}, 183.31 \pm 1$ and $183.31 \pm 3 \mathrm{GHz}$, and $183.31 \pm 3$ and $183.31 \pm 7 \mathrm{GHz}$ channels). Qiu et al. (2005) proposed the use of these differences to characterize convection as weak convection or stratiform rain, moderate convection, and strong convection. Ferraro (2004) also used, with some changes, the relationships among those differences to classify convective events. Funatsu et al. $(2007,2009)$ have further analyzed and verified the use of these differences, together with AMSU-A channels, to detect upper-level disturbances and areas of significant precipitation in the Mediterranean region.

Precipitation retrieval algorithms from AMSU/MHS measurements are based, in most cases, on three different approaches. The first is based on a physical approach and evaluates the rain rate from the relationship with the ice water path (IWP) (Weng et al., 2003; Zhao and Weng, 2002; Qiu et al., 2005; Ferraro et al., 2005; Kongoli et al., 2007), which depends on the different rain types that are identified through the differences of $183 \mathrm{GHz}$ channels, in the way mentioned above. The second approach is based on multiple linear regression with ground-based measurements. In Laviola and Levizzani (2011) the rain rate is estimated using a linear combination of the AMSU-B/MHS opaque channels at $183.31 \mathrm{GHz}$ obtained through a multiple linear regression with radar data. In Grody et al. (2000) relationships between rain rate and some scattering indexes (computed using channels $23,31,89$ and $150 \mathrm{GHz}$ ) are built and calibrated using coincident radar and rain gauge measurements. In Di Tommaso et al. (2009) the rain rate retrieval procedure is based on an extensive set of regression curves between TB differences $\left(\Delta_{17}, \Delta_{37}\right.$, and between 89 and $\left.150 \mathrm{GHz}\right)$ and surface rainfall rate in various atmospheric and surface conditions. The third approach is based on the use of NNs (Hall et al., 1999; Staelin et al., 1999; Sorooshian et al., 2000; Chen and Staelin, 2003; Hong et al., 2004; Blackwell and Chen, 2005; Sussuravadee and Staelin, 2007, 2008a, b, 2009, 2010; Krasnopolsky et al., 2008; Leslie et al., 2008). This approach originates from the consideration that an exact relation between surface rain rate and observed brightness temperatures is nonlinear and difficult to evaluate, as precipitation is one of the most difficult of all atmospheric variables to retrieve. On the other hand, NNs are widely applied in an increasing number of meteorological applications for their capability to approximate complex nonlinear and imperfectly known functions. The use of neural networks involves the training of the network with a large representative database, often obtained from numerical weather prediction model cloud-resolving simulations. Consequently, the performance of the network is largely dependent on the completeness and the representativeness of the database and on its consistency with the observations.

The purpose of this study is to describe a new algorithm based on a NN approach (Passive microwave Neural network Precipitation Retrieval - PNPR) for precipitation rate estimation applied to AMSU/MHS observations, and to examine its performance for specific case studies over the $\mathrm{Eu}-$ ropean/Mediterranean area $\left(25^{\circ} \mathrm{N}\right.$ to $75^{\circ} \mathrm{N}$ latitude, $25^{\circ} \mathrm{W}$ to $45^{\circ} \mathrm{E}$ longitude). The training of the PNPR is based on the use of a cloud-radiation database representative of the European and Mediterranean Basin precipitation climatology. It is worth mentioning that to build this database we have used the same cloud-resolving model simulations and the same radiative transfer modeling framework used for our Bayesian precipitation retrieval algorithm for conically scanning radiometers called the Cloud Dynamics and Radiation Database (CDRD) (see Casella et al. (2012, 2013), Sanò et al. (2013) and Smith et al. (2013) for a full description of the CDRD; see Mugnai et al. (2013b) for an overview of PNPR and CDRD and a description of the context leading to their development). The motivation for using a neural network algorithm for AMSU/MHS cross-track scanning radiometers stems from the fact that the changing viewing angle across a scan passage, and the concomitantly changing atmospheric path, introduce viewing-angle-dependent errors in the Radiative Transfer Equation Modeling System (RMS) calculations (see Mugnai et al., 2013b).

For conical scanners RMS-generated errors are consistent across the scan passage, and thus easily detectable as systematic errors when conducting validation checks. When viewing-angle-dependent errors enter retrievals, they compli- 
cate how systematic error should be expressed and impose a reduced confidence in formulating Bayesian probabilities.

Both CDRD and PNPR have been developed within the EUMETSAT "Satellite Application Facility on Support to Operational Hydrology and Water Management" (H-SAF, http://hsaf.meteoam.it) and are currently used operationally for producing instantaneous surface precipitation rates from conically scanning and cross-track scanning radiometers (see Mugnai et al. (2013a) for a full description of the H-SAF project and of all the precipitation products). Within the $\mathrm{H}$ SAF program the PNPR precipitation product (as well as the CDRD precipitation product) routinely undergoes a validation process carried out by the independent H-SAF Precipitation Product Validation Group (PPVG), whose composition and methodology are presented by Puca et al. (2014). It is therefore beyond the scope of this paper to carry out an extensive validation of the algorithm. The goal of the present paper is threefold: first, to describe in detail the PNPR; second, to verify the ability of a single NN for different background surfaces to recognize the different patterns and precipitation intensities in correspondence with the different surface types; and third, to verify the impact of a NN algorithm optimized for Europe on the precipitation retrieval for selected case studies, evidencing the importance of using a database representative of the area of interest for the NN training phase. Future perspectives on the use of PNPR for other parts of the globe and its application to different radiometers will be provided. As a matter of fact, the algorithm has been recently extended to cover the Meteosat Second Generation (MSG) full disk (the extended version will be soon operational within $\mathrm{H}$ SAF). Moreover, it is being modified for applications to the Suomi NPP ATMS cross-track scanner.

The PNPR algorithm is described in Sect. 2, with reference to the relevant features of the AMSU/MHS database (Sect. 2.1), the architecture of the neural network utilized and the design procedure (Sect. 2.2), and the main characteristics of the precipitation retrieval algorithm (Sect. 2.3). Section 3 concerns the verification of the retrieval and the analysis of the results, for selected case studies, compared with ground-based measurements (Sects. 3.1 and 3.2). This section presents also (Sect. 3.3) the results of a comparison with the H-SAF PR-OBS-2 v2.3 retrieval algorithm (hereafter referred to as H02 v2.3) (Mugnai et al., 2013a) and the statistical scores. Section 4 contains the conclusive remarks about the performance of the network and future perspectives.

\section{PNPR algorithm description}

PNPR optimally exploits the different characteristics of AMSU-A and MHS channels and their combinations (window channels as well as the contribution of the TB differences of the $183.31 \mathrm{GHz}$ channels, $\Delta_{17}, \Delta_{13}, \Delta_{37}$ ), with the goal of having a single neural network for different types of background surfaces (vegetated land, snow-covered surface, coast and ocean). It should be mentioned that other authors (e.g., Surussavadee and Staelin, 2008a, b) use different neural networks for different types of background (land or ocean) to deal with the very different signatures of the precipitating cloud over the two types of surfaces characterized by very different emissivities. However, the use of different networks for different backgrounds can lead often to discontinuity of the estimates in correspondence with transitions between these two types of surface. The approach of a single NN prevents precipitation estimates from being inconsistent when an observed precipitation system extends over two or more types of surfaces.

\subsection{The training database}

The use of neural networks involves a "training phase" using a large sample of data representative of the input and the output variables used in the retrieval process (in this case AMSU/MHS TBs and surface precipitation rate, respectively). The performance of the NN is largely dependent on the completeness and representativeness of the database for the area of interest and on its consistency with the actual observations. In PNPR this data set is obtained from a cloud-resolving model coupled to a radiative transfer equation (RTE) model used to simulate brightness temperatures consistent with the scan viewing geometry and channel frequencies of AMSU-A and MHS (following the methodology similar to that described by Sanò et al. (2013) and Casella et al. (2013)). The database includes 60 cloud-resolving simulations of different precipitation events over the Europe and Mediterranean area carried out with the University of Wisconsin Nonhydrostatic Modeling System (UW-NMS) cloudresolving model (Tripoli, 1992; Tripoli and Smith, 2014a, b). All the details about the cloud model configuration setup are provided by Casella et al. (2013).

Figure 1 shows the seasonal and spatial distribution of the inner domains. In essence, the database has been created for the European region, covering the different seasons (15 simulations in each season) and different meteorological situations and precipitation regimes. Each simulation runs for 24 or $36 \mathrm{~h}$ with a $12 \mathrm{~h}$ spin-up time. The NOAA National Center for Environmental Prediction (NCEP) Global Forecasting System (GFS) gridded analyses at $0.5^{\circ}$ resolution were used as initial conditions and to nudge the boundaries of the outer grid every $6 \mathrm{~h}$ throughout the simulation period.

The simulated satellite TB vectors are consistent with the AMSU-A and MHS (or AMSU-B) channel frequencies, viewing angles and viewing-angle-dependent IFOV sizes along the scan projections. Both AMSU-A and MHS have a swath of about $2200 \mathrm{~km}$ and a scan angle of $\pm 48^{\circ}$ from nadir. AMSU-A takes 30 cross-track measurements and has a near-nadir spatial resolution of $48 \mathrm{~km}$, while MHS (AMSUB) takes 90 measurements and has a near-nadir spatial resolution of $16 \mathrm{~km}$. These cross-track scanners provide images 


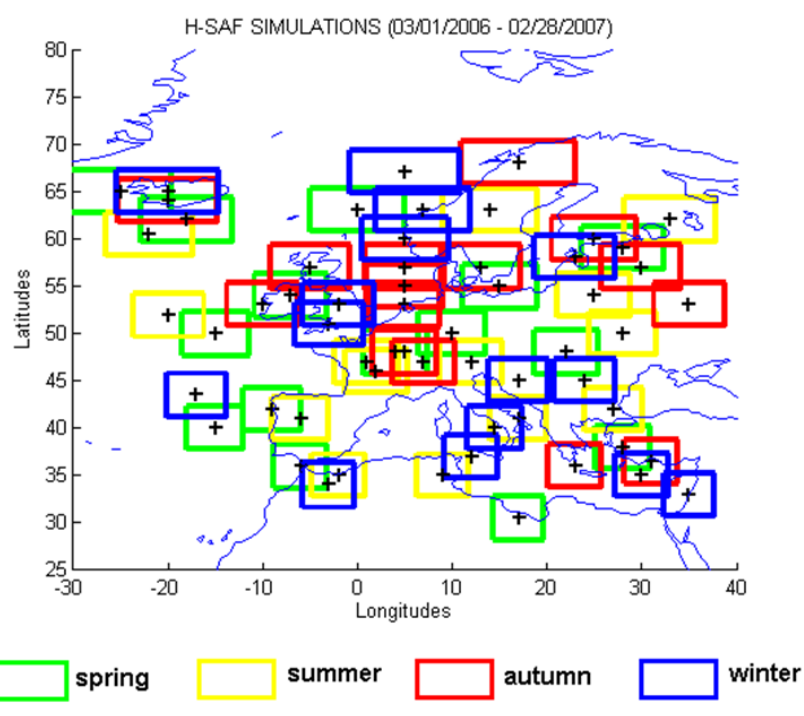

Figure 1. Inner domains of the 60 NMS simulations, divided by season.

with constant angular sampling along the scan $\left(1.1^{\circ}\right)$, implying that the instantaneous field of view (IFOV) elongates as the beam moves from nadir toward the edge of the scan. The elongation is such that for AMSU-A the IFOV at the edge of the swath is $80 \mathrm{~km} \times 150 \mathrm{~km}$ and for MHS (and AMSU-B) is $27 \mathrm{~km} \times 50 \mathrm{~km}$.

The correspondence between TB vectors and their associated surface precipitation rates is complicated by the dependence of spatial resolution along the radiometer scan due to the varying viewing angle. A variable sensor resolution (VSR) was defined according to the nominal resolution of AMSU-B/MHS, varying from $16 \mathrm{~km} \times 16 \mathrm{~km} /$ circular at nadir to $26 \mathrm{~km} \times 52 \mathrm{~km} /$ elliptical at scan edge. Thus, the cloud-model high-resolution surface precipitation rates (and associated environmental and microphysics vertical profiles) were averaged over 45 VSRs and the simulated TBs were calculated at 45 different viewing angles. In all, the database contains some 2.5 million entries for the European/Mediterranean Basin region and has 45 views for each entry. Details about the radiative transfer model, singlescattering parameterization, and surface emissivity parameterization are provided by Casella et al. (2013). It is worth noting that NNs are able to handle such large databases being at the same time computationally very efficient.

\subsection{The neural network}

The neural network is a highly flexible tool alternative to regression and classification techniques. It allows approximating unknown, complicated nonlinear functions to an arbitrary degree of accuracy (Hsu et al., 1997; Shi, 2001; Chen et al., 2006; Bellerby, 2007; Marzban, 2009).

Figure 2 shows a feedforward multilayer neural network with $n_{i}$ inputs; $n_{1}$ nodes in the first (input) layer (nodes are called also perceptrons or neurons); $n_{2}$ and $n_{3}$ nodes in the second and third layer (hidden layers), respectively; and one output layer. Each node has its own transfer function. The nodes are connected by links that transfer the weighted output of a node to the linked nodes of the following layer. In this following layer, each node receives, as input to its transfer function, a weighted sum of the outputs of the previous layer. The output of the transfer function corresponds to the output of each node. For example, the output of a node ( $k$ th), $y_{k}$, of the first hidden layer takes the form

$y_{k}(\omega, x)=f_{2}\left[\sum_{j=1}^{n_{1}} \omega_{k j} \times f_{1} \times\left(\sum_{t=1}^{n_{i}} \omega_{j t} \times x_{t}+b_{1}\right)+b_{2}\right]$,

where $x_{t}$ are the input signals ( $n_{i}$ values), $\omega_{j t}$ are the weights connecting the inputs to the nodes of the input layer and $\omega_{k j}$ the weights connecting the nodes of the input layer to the nodes of the first hidden layer, $f_{1}$ and $f_{2}$ are the transfer functions of the input layer and the first hidden layer, and $b_{1}$ and $b_{2}$ are the bias of nodes of the two layers.

The estimation of the weights is performed in the training phase. During this phase a training database is used (providing the network with synthetic input and output data).

In the backpropagation network, during the training (Levenberg-Marquardt algorithm), when the network is given an input, the signal propagates forward from the input layer of nodes, through each internal layer, to the output layer. The node in the output layer produces an output $\left(y_{i}\right)$, which is compared to the $i$ th target output $\left(t_{i}\right)$ defined in the training set. An error value is calculated as

$E=\frac{1}{n} \sum_{i=1}^{n}\left(y_{i}-t_{i}\right)^{2}$,

where $n$ is the number of elements of the training set. The network corrects its weights to lessen the errors. The correction mechanism starts with the output neuron and propagates backward through each internal layer to the input layer, modifying the value of each weight (i.e., $\omega_{i j}$ ) in relation to its contribution to the error $\left(\frac{\partial E}{\partial \omega_{i j}}\right)$. The iteration continues in order to minimize the error.

The design of the network architecture is normally determined empirically. Model selection in neural networks aims at finding as few hidden units and connections as necessary for a good approximation of the true function. This selection includes two relatively distinct aspects: determining how many layers to use and determining how many nodes to include in each layer. Unfortunately, this is not a simple problem and turning to an empirical approach is often the most reasonable way. In this study the model selection has been carried out using a cross-validation method (Anders and Korn, 1999; Marzban, 2009). In the cross-validation strategy the comparison between two models is based on the mean square prediction error (MSPE), which is obtained applying the model to different validation sets. For this purpose 


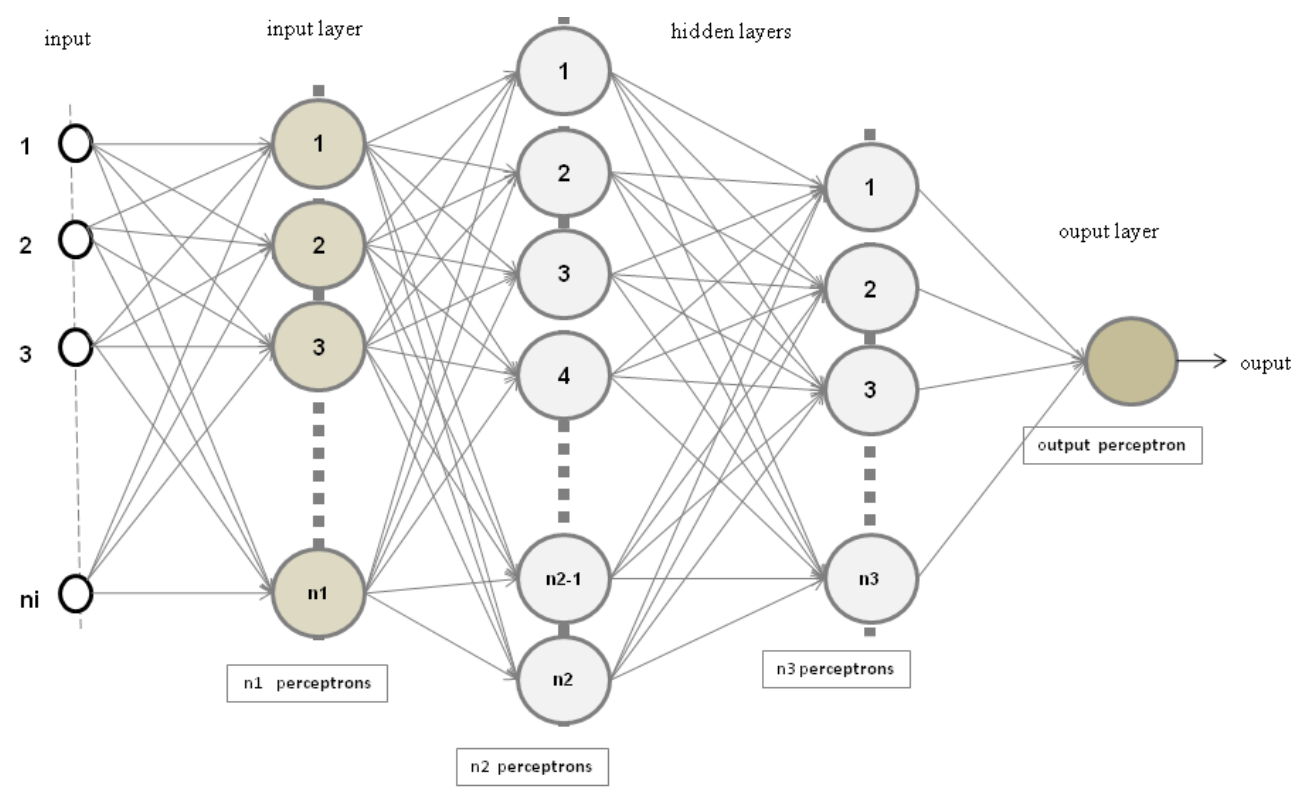

Figure 2. Schematic diagram of a multilayer neural network (two hidden layers).

a test data set is used, divided into $M$ subsets containing $n$ observations each. The model is repeatedly re-estimated using different data set of $n(M-1)$ observations, leaving out a different subset each time. The average MSPE defines the cross-validation error, CV (Anders and Korn, 1999):

$\mathrm{CV}=\frac{1}{M} \sum_{m=1}^{M} \mathrm{MSPE}_{m}$

In the cross-validation methodology, the first step consists in determining the number of hidden layers. Starting from a simple architecture, two models are compared, one of which contains an additional hidden unit. For both the models the $\mathrm{CV}$ is evaluated and, if the more complex unit shows a smaller CV error, the additional hidden layer is accepted. The procedure stops when no further hidden layer is able to reduce the $\mathrm{CV}$ error. At this point, with a similar procedure, the number of nodes is optimized in each layer. The second step aims at determining the input connections. To find irrelevant connection, one input is removed and the resultant $\mathrm{CV}$ is compared with that of the complete network. In this way all the models with one input connection removed are analyzed and the model with the lowest CV error is accepted. At the end of this second step, no input connection can be removed without increasing the $\mathrm{CV}$ error. Considering that there is a trade-off between the two steps, because the number of layers and the number of nodes in each layer are interdependent, the design tactic requires alternately tuning the number of layers, the number of nodes and the number of inputs (Young, 2009).

Because of the complexity of this method, in designing the network it was considered necessary to impose some constraints on both the input variables and the learning procedure. Preliminarily, it should be mentioned that the goal was to use a single neural network for all background surfaces (vegetated land, snow-covered surface, coast and ocean) and that the network output is the estimated surface precipitation rate.

With regard to the input variables, we started considering all the brightness temperatures of AMSU-A and MHS channels, together with the $183 \mathrm{GHz}$ channel differences $\left(\Delta_{17}\right.$, $\left.\Delta_{13}, \Delta_{37}\right)$ and some ancillary data, such as latitude, longitude, surface height, the background surface type, season, pixel number and the secant of the zenith angle along the AMSU/MHS cross-track scan. Geographical and meteorological parameters were introduced in order to mitigate against the ambiguity intrinsic to the PMW precipitation retrieval process (e.g., Panegrossi et al., 1998). Pixel number and secant of the zenith angle were also needed to determine the correction of the limb smearing on the TBs, an effect produced by the changing atmospheric path length along the scan (Goldberg et al., 2001). The training procedure was carried out also to have this effect taken into account and corrected within the neural network itself. Principal component analysis (PCA) (Jolliffe, 2002) was performed on AMSUA/MHS channels to explore the possibility of decreasing the number of inputs, of reducing the effect of surface emission variability on the measured TBs and consequently of improving the network performance in retrieving surface precipitation (Surussavadee and Staelin, 2008a). Canonical correlation analysis (CCA) (Hair et al., 1998; Wilks, 1995) was also carried out to find the linear combination of the TBs (canonical variable) of the various channels with maximum correlation with the surface precipitation. Particularly, we chose to use the CCA methodology for measuring canonical correlations existing, in the database, between different channel 
combinations and the surface rain rate. Through this procedure, by eliminating the channel combinations with a relatively low correlation, we have built the most effective input canonical variable to the NN.

In the application of the cross-validation method, in order to find the minimum number of useful inputs among all the variables initially considered, we imposed the use of the three inputs $\Delta_{17}, \Delta_{13}$ and $\Delta_{37}$. This constraint is related to one of the objectives of this research, namely the evaluation of the effectiveness of all these inputs in detecting precipitation areas (Hong et al., 2005; Funatsu et al., 2007, 2009). The selection of the optimal inputs, with the cross-validation method, was consequently affected by this constraint. Some of the proposed variables were not very effective on the performance of the network. Particularly, the principal components (PCs) were not significant as expected (especially for the retrieval of weak and stratiform precipitation), probably because of the a priori condition of using a single network for all background surfaces. In fact, different PCs would have been selected as optimal (in terms of different TB combinations and different order) depending on the type of surface (as obtained in Surussavadee and Staelin, 2008a).

During the training phase, several preliminary tests were carried out to avoid the overfitting, i.e., the loss in generalization ability of the network. This phenomenon can reduce the output errors in a synthetic application (when the NN is applied to the training database), but it increases the errors if the NN is applied to data not included in the training database. This is linked, in addition to the structure of the network (number of hidden layers and nodes), also to the training procedure (an excess of iterations in the training, also called overtraining). The overtraining forces the $\mathrm{NN}$ to learn the fine structure that is generated by noise.

As a result of preliminary tests, some criteria for the training procedure have been defined. The first criterion concerns the division of the training database into three pieces: the ground truth (training) piece to be used for the actual training, the validation piece for providing the synthetic TBs used in a subsequent verification analysis, and the test piece for providing the TBs for the comparison of the different models. Notably, all three pieces need to be representative of all precipitation events contained within the collective database. The choice of the size and of the specific members of each piece is thus crucial in obtaining an effective evaluation of the final NN's performance. Consequently, a statistical analysis was performed on each piece to check their representativeness of the different typologies of simulated events, and of the whole range of precipitation rates. The second criterion concerns the early-stopping method, i.e., the interruption of the training before complete convergence has occurred. Through various experimental tests the earlystopping method was refined in order to improve the generalization ability of the NN, in view of the size (several millions of profiles) and complexity (wide range of the precipitation values and different viewing angles) of the training database.
In particular, we have found some optimal conditions for the gradient of the performance function of the NN (the performance function is represented by the mean squared error (mse)) and for the number of iterations (epochs) during the training. In fact, these two parameters provide an indication on the quality of the learning process of the network. The number of epochs was limited in the range 500-1000, and the minimum value of the gradient of performance (mse) was fixed to 0.05 . The correlation coefficient $(R)$ evaluated in the training data set was limited to 0.90 , while the corresponding minimum value in the validation data set was set at 0.80 . These values correspond to a balance between an appropriate learning level and a good generalization ability of the NN.

During the phase of network design and the training process, more than 200 architectures have been tested and an optimal neural network has been obtained, where "optimal" refers to the best performance of the network (i.e., minimum $\mathrm{CV}$ over the full dynamic range of the inputs, absence of overfitting and absence of anomalous inhomogeneities in the retrievals) (Staelin and Surussavadee, 2007).

In order to reduce the complexity of the network, only the input variables showing the largest impact on the results have been selected. As a result, nine input variables are used in the $\mathrm{NN}$ :

1. a linear combination of TBs (LCT) at 50.3, 89 and $150 \mathrm{GHz}$ whose coefficients are obtained from the CCA with respect to the surface rain rate (these channels showed the highest correlation coefficients in the CCA analysis in the database for all types of background surfaces);

2. $\Delta_{17}$ difference between the TBs of channels $183.31 \pm 1$ and $183.31 \pm 7 \mathrm{GHz}$;

3. $\Delta_{37}$ difference between the TBs of channels $183.31 \pm 3$ and $183.31 \pm 7 \mathrm{GHz}$;

4. $\Delta_{13}$ difference between the TBs of channels $183.31 \pm 1$ and $183.31 \pm 3 \mathrm{GHz}$;

5. surface type (land, sea, coast);

6. latitude;

7. season;

8. surface height (altitude);

9. secant of the zenith angle.

The network has two hidden layers. In the first layer (the input layer) the number of nodes equals the number of inputs. For the second and third layers (the hidden layers), 20 and 8 nodes are selected, respectively. The tan-sigmoid transfer function is used for the input and the hidden layers, while a linear transfer function is used for the output node. 
PMW Neural-net Precipitation Retrieval (PNPR) Algorithm

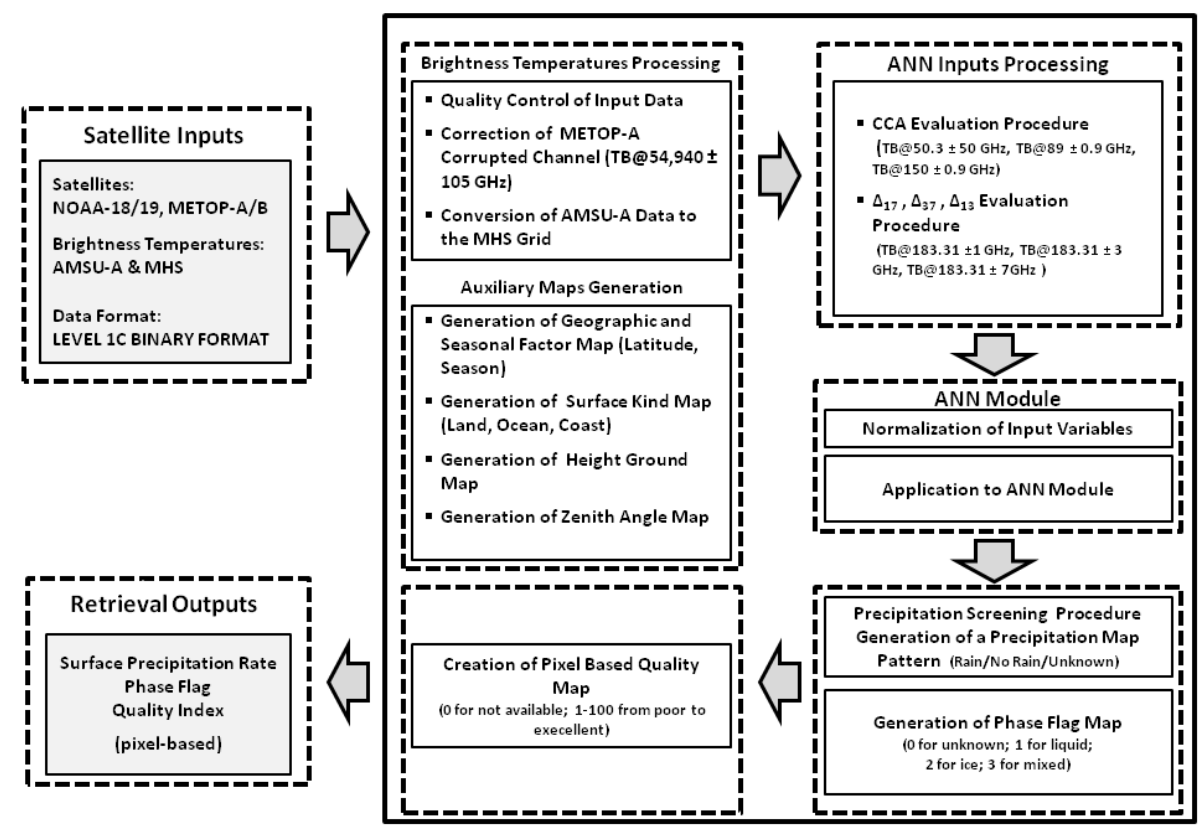

Figure 3. Flow diagram of the PNPR algorithm.

\subsection{PNPR flow diagram description}

Figure 3 shows the flow diagram of the PNPR algorithm.

The PNPR algorithm receives as input the TBs (level 1c data) measured by radiometers AMSU-A and MHS currently aboard the U.S. NOAA-18 and NOAA-19 and the EUMETSAT MetOp-A MetOp-B satellites.

A first check (brightness temperatures processing block) is carried out on the TBs, and pixels with any TB value less than $50 \mathrm{~K}$ or greater than $400 \mathrm{~K}$ are discarded and not considered for the retrieval (see Ferraro et al., 1998; Surussavadee et al., 2012). Moreover, the input TBs undergo a quality check to remove those deriving from occasionally corrupted channels. Furthermore, a dedicated NN corrects the TB of channel 7 (corresponding to $54.94 \mathrm{GHz}$ ) of the MetOp-A satellite using other channels in the oxygen band. AMSU-A data are gridded to the MHS data grid using a bilinear interpolation. A second step involves the generation of the auxiliary maps (auxiliary maps generation block). The algorithm generates five maps: the geographical map (latitude), the seasonal map, the surface type map (land, ocean, coast), the orography map (surface height) and the zenith angle map. The surface type map does not contain information on the presence of snow/ice at the surface. The identification of this condition is assigned to the PNPR algorithm itself. The third step (NN inputs processing block) is the evaluation of the NN inputs LCT, $\Delta_{17}, \Delta_{37}$ and $\Delta_{13}$. The fourth step (NN module block) involves the normalization of the inputs and the surface precipitation rate evaluation using the NN. The fifth step involves a screening test for identifica- tion of potentially precipitating pixels. The screening procedure used is based on the method described by Chen and Staelin (2003), which uses the comparison of the TBs at $183 \pm 7$ or $183 \pm 3 \mathrm{GHz}$ with different thresholds depending on the zenith angle and the spatially filtered limb-corrected TB at $53.6 \mathrm{GHz}$, obtained by selecting the highest brightness temperature within a $7 \times 7$ array of MHS pixels (hereafter, $\left.T_{53.6}^{\max }\right)$. The full description of the screening procedure is provided by Mugnai et al. (2013b).

The precipitation map, obtained from the screening procedure, is used to filter the NN output (which includes all the pixels of the satellite swath), setting to 0 the rain rate values of the pixels resulting with no rain. An additional output (generation of phase flag map block) provided by the algorithm is the indication of the phase of the precipitation: liquid, solid, mixed or unknown (when the phase determination procedure is not applicable). The determination of the phase flag is based on the studies on snow and ice detection of Surussavadee and Staelin (2009), Rosencrantz (2003) and Kongoli et al. (2003), and with reference to the indexes defined by Grody et al. (2000) for the identification of presence of a snowy and iced background (this information is used in the quality map definition). In these studies snowfall is detected using TBs at 20.3, 50.3 and $89 \mathrm{GHz}$, and combinations of these channels. The phase flag is evaluated only for pixels flagged as precipitating after the screening procedure, and it is not available over coastal background surfaces.

In a subsequent step (creation of pixel-based quality map) the algorithm provides a quality flag to be associated with the retrieval, providing immediate indication of areas or con- 
ditions where the retrieval is more or less accurate. The quality flag (poor, fair, good or missing) is based on a percentage confidence index (PCI) describing both the product quality and reliability, based on four different criteria:

1. quality of input data (used sensor, type and number of channels used, horizontal resolution, malfunctioning of radiometers);

2. background surface index (type of surface, snowy/iced background);

3. event type index (snow storm, stratiform rain, convective cells);

4. internal algorithm performance index (i.e., dependence on scan viewing angle).

The PCI evaluation is carried out through the following steps:

1. A preliminary PCI value is assigned with different criteria depending on the output of the screening procedure:

- For no-rain pixels a preliminary value of the PCI is evaluated according to some conditions on the $\mathrm{TB}_{53.6}^{\max }$ provided in Table 1. The presence of snow/ice on the background surface lowers the value of the PCI, which is limited to 10 .

- For rainy pixels the PCI value is based on a procedure that identifies the event typology. This procedure (Funatsu et al., 2007, 2012) classifies four typologies of precipitation - not identified/light stratiform, stratiform, convective and heavy convective (overshooting top) - and associates a preliminary value of the PCI according to the values listed in Table 2. Also in this case, the presence of snowy/iced background on area with precipitation lowers the value of the PCI (the PCI value is limited to 10). The preliminary PCI value associated with precipitation on coastal area has an upper limit equal to 30 (quality flag "fair").

2. The preliminary PCI value is combined to some correction coefficients to become the final value of the PCI:

- satellite operation status coefficient (the PCI value decreases when satellite has some problem, e.g., damaged channels);

- scan geometry coefficient (the PCI value decreases as the scan viewing angle increases);

- data quality coefficient (the PCI is set to 0 in the case of corrupted channels and/or unrealistic values of measured TBs).
Table 1. Preliminary PCI thresholds based on screening algorithm.

\begin{tabular}{lll}
\hline Test on TB & Environmental situation & $\begin{array}{l}\text { Preliminary } \\
\text { PCI }\end{array}$ \\
\hline $\mathrm{TB}_{53.6}^{\max }<242 \mathrm{~K}$ & $\begin{array}{l}\text { very cold/dry } \\
\text { (precipitation retrieval } \\
\text { not available) }\end{array}$ & 0 \\
& cold/dry situation & 20 \\
\hline $\mathrm{TB}_{53.6}^{\max } \geq 242 \mathrm{~K}$ and & \\
$\mathrm{TB}_{53.6}^{\max }<248 \mathrm{~K}$ & warm/wet situation & 50 \\
\hline $\mathrm{TB}_{53.6}^{\max } \geq 248 \mathrm{~K}$ & & \\
\hline
\end{tabular}

Table 2. Preliminary PCI based on precipitation type.

\begin{tabular}{lr}
\hline Typology of event & Preliminary PCI \\
\hline Not identified/light stratiform & 40 \\
Stratiform & 50 \\
Convective & 90 \\
Heavy convective & 90 \\
\hline
\end{tabular}

\section{Case studies}

In this section we analyze the results of the PNPR algorithm for four precipitation events characterized by different meteorological conditions. The precipitation events were selected from those used in the verification study described in Panegrossi et al. (2013). In that study the two currently operational H-SAF PMW precipitation products (the PNPR algorithm for AMSU/MHS measurements, and the Bayesian CDRD algorithm (Sanò et al., 2013; Casella et al., 2013) for SSMIS measurements) were analyzed and compared to ground-based measurements provided by the H-SAF Precipitation Product Validation Team (PPVT). The study was carried out for several case studies representative of the different environmental and meteorological situations in Europe and in the Mediterranean area. In the present paper we focus on the results of PNPR also in relation to the selection procedure of the NN input variables discussed in Sect. 2.2.

\subsection{Ground-based data processing}

As ground truth, both radar and rain gauge data are used for comparison with the PNPR retrievals. It is worth noting, however, that precipitation measurements from groundbased observations are subject to large uncertainty and tha comparison with satellite-based retrievals is very problematic (e.g., Smith et al.,1998; Anagnostou and Krajewski, 1999; Kummerow et al., 2000; Lin and Hou, 2008; Rinollo et al., 2013; Porcù et al., 2014). Puca et al. (2014) have raised several issues related to the use of radar and rain gauge data for satellite-based precipitation product validation, and within the H-SAF validation program a common validation protocol (i.e., common code for data processing, quality control of data) has been adopted in order to prevent some of the prob- 
lems. However, some of the issues inherent to the groundbased system used always need to be taken into account when comparing satellite-based and ground-based precipitation data. These issues include (1) the lack of consistency between gauges and radar in several cases; (2) problems with radar measurements, such as beam blocking in mountainous regions, lack of intercalibration among different radars or among different networks and uncertainty of precipitation estimates particularly critical in the presence of snowfall; and (3) problems with rain gauge measurements, such as sparse network, different time integration among stations and different instruments (i.e., heated or not-heated). These issues have been considered in the analysis of the PNPR results described in this section.

In order to maintain the satellite precipitation retrieval at its native resolution, both radar and rain gauge data are averaged according to a procedure developed in collaboration with the H-SAF validation team. The radar and rain gauge data are averaged using a 2-D Gaussian function with an elliptic horizontal section approximating the MHS radiometer antenna pattern, elongating as the beam moves from nadir toward the edge of the scan, from $16 \mathrm{~km} \times 16 \mathrm{~km} /$ circular at nadir to $26 \mathrm{~km} \times 52 \mathrm{~km} /$ elliptical at scan edge, and rotated accordingly to the actual satellite scan orientation at the ground (see Puca et al., 2014).

\subsection{Discussion and qualitative comparison with ground-based measurements}

Four of the case studies presented in Panegrossi et al. (2013) are considered: a flood-producing storm, a convective precipitation event, a moderate/light stratiform precipitation event and a cyclone system causing several thunderstorms with heavy precipitation. In this section a qualitative assessment of the results and eye-balling comparison with ground-based measurements will be carried out, a more quantitative analysis (with dichotomous and continuous statistical scores) will be provided in Sect. 3.3.

The first case study concerns an intense flood event in northwestern Italy, affecting the eastern Liguria region and northern Tuscany on 25 October 2011. A widespread trough extending from the North Atlantic entered on the west Mediterranean, inducing wet and persistent southwesterly flow over Italy. A cold front system, associated with this lowpressure area, arrived in the central-western Mediterranean. The cold front was preceded by intense moist and unstable currents, from the southeast, in the lower layers, scrolling from the Tyrrhenian to the Ligurian Sea (Fig. 4, left panel). The flow at high altitude with a southwesterly direction, controlled by the polar jet, resulted, within the cloud layer, in the formation of a thunderstorm line that has assumed a configuration of supercell, particularly around the city of La Spezia. The slow cyclonic rotation around the low-pressure system has made stationary cold front for about $15 \mathrm{~h}$ in the same area, resulting in persistent rain, interspersed with intense
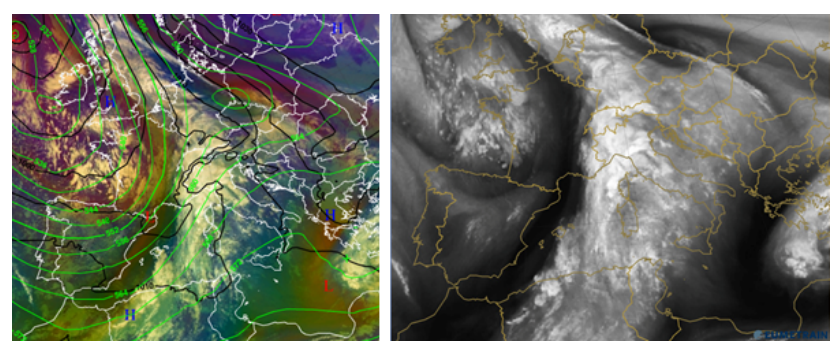

Figure 4. 25 October 2011, 12:00 UTC: (left) air mass RGB EUMETSAT product from MSG SEVIRI, mean sea level pressure (black contour lines) and geopotential height at $500 \mathrm{hPa}$ (green contour lines) from ECMWF analysis and (right) MSG water vapor image at $6.2 \mu \mathrm{m}$ (EUMeTrain, www.eumetrain.org).

storm events. The orographic and surface heating forcing supported local development of convective cells over Liguria. Peaks of accumulated rain ranging between 300 and $550 \mathrm{~mm}$ in $24 \mathrm{~h}$ were registered by rain gauges to the north and over the Cinque Terre area (east of the Liguria region) (Rebora et al. 2013).

Figure 4 (right panel) shows the MSG SEVIRI WV $(6.2 \mu \mathrm{m})$ image. The edges of the dry area (dark) correspond to stratospheric (dry) air protruding down adjacent to the region of intense convective activity. This region, extending from the Tyrrhenian Sea to the northeast of Italy, is well identified in Fig. 5, which shows MHS images from the NOAA19 satellite overpass at 11:44 UTC. It is characterized by the strong TB depression at $150 \mathrm{GHz}$ (Fig. 5, left panel) and by the TB depression at $183.31 \pm 3 \mathrm{GHz}$, identifying the most intense convective cells (Fig. 5, right panel) along the thunderstorm line. The dry stratospheric air intrusion is evident also in the $183.31 \pm 3 \mathrm{GHz}$ image (dark red areas).

Figure 6 shows the result of the LCT and the differences $\Delta_{13}, \Delta_{37}$ and $\Delta_{17}$, representing the four NN inputs derived from the AMSU-A/MHS TBs. The two top panels show the signal due mostly to the lower layers of the atmosphere, near the surface for the LCT (the window channels 50.3, 89 and $150 \mathrm{GHz}$ contribute to this parameter), highly correlated with the precipitation, and in the lower atmosphere for the $\Delta_{37}$ difference. The effect of surface emissivity is more evident in the LCT panel. In the bottom left panel the $\Delta_{13}$ difference shows the situation in the layers of the atmosphere higher than those of the two top panels (the height of the layers depends on the atmospheric moisture conditions). The impact is evident on $\Delta_{37}$ of the most intense convection over La Spezia and west of Corsica (red areas), while less intense areas of precipitation (i.e., in the eastern Mediteranean) are much less evident. The difference $\Delta_{17}$, in the bottom right panel, shows higher sensitivity than the other two in the area of the flood. As already mentioned, the trends of these three differences, their magnitudes and reciprocal relationships provide important information on the characteristics (extent, intensity and structure) of the precipitation (Wang et al., 1997; Burns et 

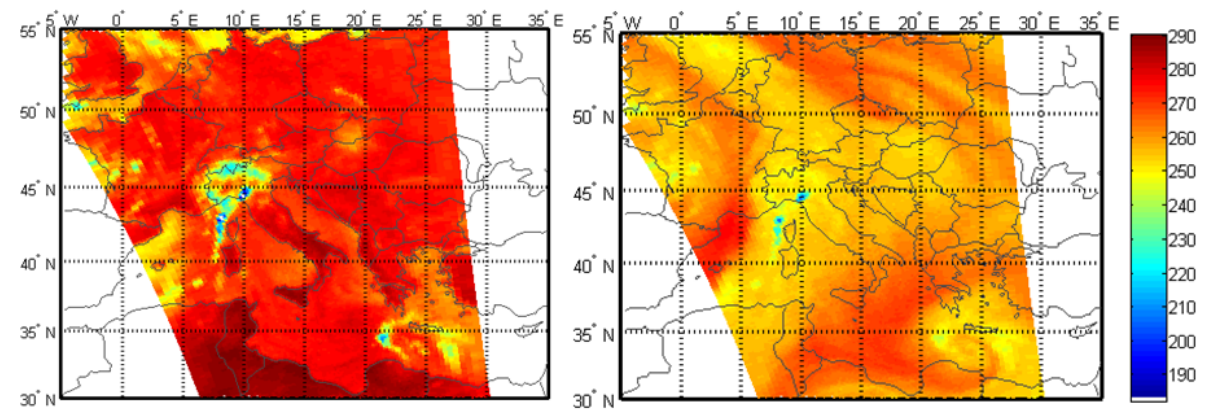

Figure 5. Intense convective precipitation with a flood occurring over the La Spezia area (Italy, $44^{\circ} \mathrm{N}, 10^{\circ} \mathrm{E}$ ) on 25 October 2011 . AMSU-B (NOAA 19), 11:44 UTC: TB (K) at $150 \mathrm{GHz}$ (left panel) and TB (K) at $183.31 \pm 3 \mathrm{GHz}$ (right panel).
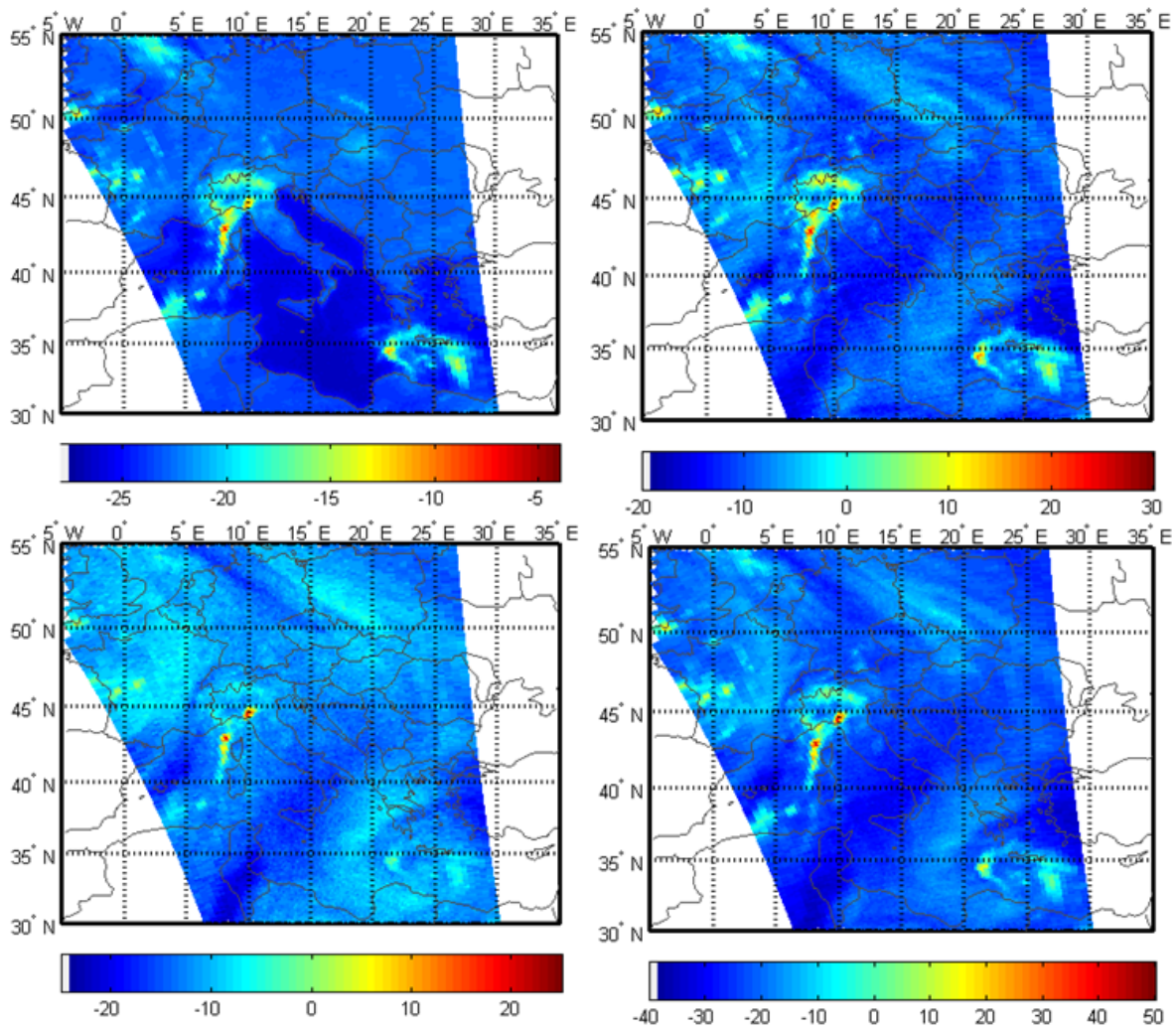

Figure 6. Flood over the La Spezia area (Italy, $44^{\circ} \mathrm{N}, 10^{\circ} \mathrm{E}$ ), 25 October 2011, 11:44 UTC. Maps of the four inputs data to the NN derived from the AMSU-A/MHS TBs: LCT (top left), $\Delta_{37}$ (top right), $\Delta_{13}$ (bottom left) and $\Delta_{17}$ (bottom right).

al., 1997; Hong et al., 2005; Qiu et al., 2005; Funatsu et al., 2007). The positive differences of all $\Delta_{13}, \Delta_{37}$ and $\Delta_{17}$ correspond to areas of deep convection, in agreement with Hong et al. (2005) and the analysis of Funatsu et al. (2009) in the Mediterranean region.

Figure 7 (top left panel) shows the PNPR surface precipitation retrieval $\left(\mathrm{mm} \mathrm{h}^{-1}\right)$ over Italy and in the area hit by the flood for the 11:44 UTC overpass. The precipitation pattern follows the thunderstorm line evidenced in the previous figures, and the precipitation values exceeding $10 \mathrm{~mm} \mathrm{~h}^{-1}$ correspond to the areas with larger TB depression at $150 \mathrm{GHz}$
(Fig. 5) and evidenced as positive difference areas of $\Delta_{13}$, $\Delta_{37}$ and $\Delta_{17}$ in Fig. 6. In the top right panel of Fig. 7 the map of the PCI is shown. The confidence in the retrieval is very high in correspondence with the areas of more intense precipitation, while it tends to decrease in the coastal area, where the reliability of the retrieval is lower. In the bottom panels of Fig. 7 the PNPR rain rates are compared to the rain gauge measurements. Porcù et al. (2014) have shown that an integration time interval between 0.5 and $1 \mathrm{~h}$ of rain gauge measurements is needed for an optimal comparison between a typical quasi-instantaneous PMW precipitation product (at 
low spatial resolution) and local rainfall accumulation measurements from rain gauges. They also show that the use of two rain gauges instead of one within the satellite IFOV generally decreases the errors related to rain gauges network spatial distribution. In the left panel the PNPR-retrieved surface precipitation $\left(\mathrm{mm} \mathrm{h}^{-1}\right)$ over land is shown only in correspondence with the IFOVs where at least two rain gauges were available. The bottom right panel shows rain gauge precipitation in the 60 min cumulation interval around the time of the satellite overpass, spatially averaged over the satellite IFOVs as described in Sect. 3.1. When comparing the two panels, a fairly good agreement is evident in the areas with the most intense precipitation. The difference in precipitation measured on the west side of the coast of Liguria is linked to the uncertainty in the identification of coastal area and in the corresponding retrieval. There are some areas of light precipitation (northeast of Italy $\left(46^{\circ} \mathrm{N}, 13^{\circ} \mathrm{E}\right)$ and southern coast of the Calabria region $\left(39^{\circ} \mathrm{N}, 17^{\circ} \mathrm{E}\right)$ ) of missed precipitation by PNPR. In these regions light cumulated precipitation is registered by the rain gauges. Such a discrepancy might be due to the different nature of the measurements by the satellite (quasi-instantaneous) and the gauges (integrated in time). Areas of false alarm (precipitation detected by the satellite and not measured by the rain gauges) are limited to regions with very light precipitation in central Italy and Sardinia and are due to weaknesses in the screening procedure, more critical when the signal due to the precipitation is weak compared to that of the surface background.

A second case study concerns a convective precipitation case that occurred over Germany on 7 August 2010. A baroclinic zone coming from the Baltic Sea reached Poland and the Czech Republic and moved up to Austria. In the same area sub-tropical air was advected from south to north on the east side of the associated low pressure.

On 7 and 8 August 2010 the precipitation reached high values $(150 \mathrm{~mm}$ in $48 \mathrm{~h}$ ) in parts of Germany, especially in Saxony, causing floods in the upper parts of the rivers Neiße, Spree and Elbe with catastrophic damages (Rachimow and Krahe, 2011). Also in this case we have verified that the four inputs to NN derived from AMSU-A and MHS TBs identify in a correct way the precipitation system (not shown). Figure 8 shows the TB (K) image at $150 \mathrm{GHz}$ from MHS (MetOp-A) (top left panel), at 09:51 UTC on 7 August. The area affected by the convective event (mostly in the Czech Republic) is highlighted by the TB depression at $150 \mathrm{GHz}$. The PNPR surface precipitation rate estimate $\left(\mathrm{mm} \mathrm{h}^{-1}\right)$ (top right panel) shows values of precipitation up to $12 \mathrm{~mm} \mathrm{~h}^{-1}$ in the same area. Rectangles in the panels show the approximate area covered by the radar measurements. Bottom panels present in detail the results in the area included in the rectangles. Comparing the radar measurements (bottom right) with the PNPR retrieval (bottom left), the ability is evident of PNPR to distinguish between the two precipitation regimes observed by the radar. Overall, a good agreement is evident, but there is an underestimation of the precipitation in PNPR
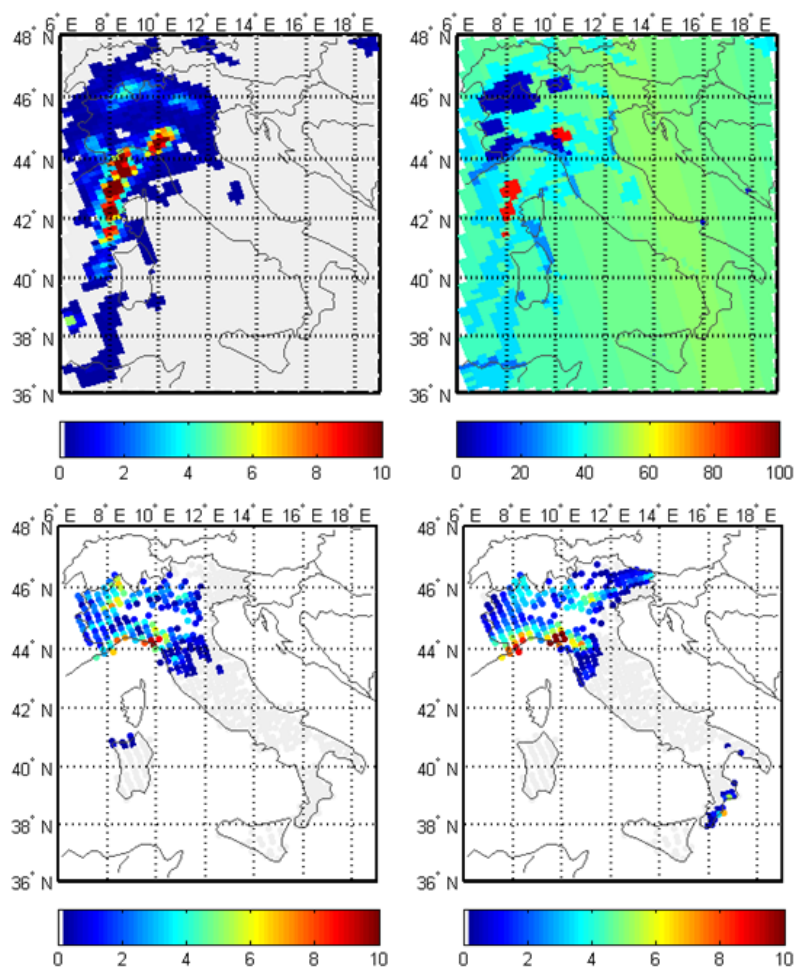

Figure 7. Flood over the La Spezia area (Italy, $44^{\circ} \mathrm{N}, 10^{\circ} \mathrm{E}$ ), 25 October 2011, 11:44 UTC. PNPR surface precipitation rate $\left(\mathrm{mm} \mathrm{h}^{-1}\right)$ (top left panel), "quality index" (top right panel), PNPR surface precipitation rate $\left(\mathrm{mm} \mathrm{h}^{-1}\right)$ over land (bottom left) for comparison with rain gauges data and $1 \mathrm{~h}$ cumulated precipitation (11:0012:00 UTC), from rain gauges, averaged over the IFOV and sampled (bottom right).

in the most intense areas, partly due to the low spatial resolution of the MHS IFOV compared to the radar.

A third case study concerns a stratiform precipitation that occurred over Hungary on 1 December 2009. Light stratiform precipitation over land represents a situation where usually PMW retrievals have large uncertainties, mostly because of the low TB contrast between the precipitating cloud (characterized by low-density iced hydrometeors with reduced TB depression at high frequencies) and the land surface background. The microwave signal corresponding to rainy pixels is very weak and is often difficult to discriminate it from rainfree pixels in the screening procedure.

In Fig. 9 the values of LCT (top left) and of $\Delta_{17}$ (top right) are presented. In both panels, the patterns of precipitation over Hungary are shown in a consistent manner (black rectangle). The LCT, although more sensitive to the surface emissivity, correctly identifies the area of stratiform rain. Moreover, in both panels even the most intense portions of the perturbation system, extending southward (out of the range of the radar) and in the Mediterranean north of the African coast, is evident in both images, showing high sensitivity of $\Delta_{17}$ to the convective areas. In the middle left 

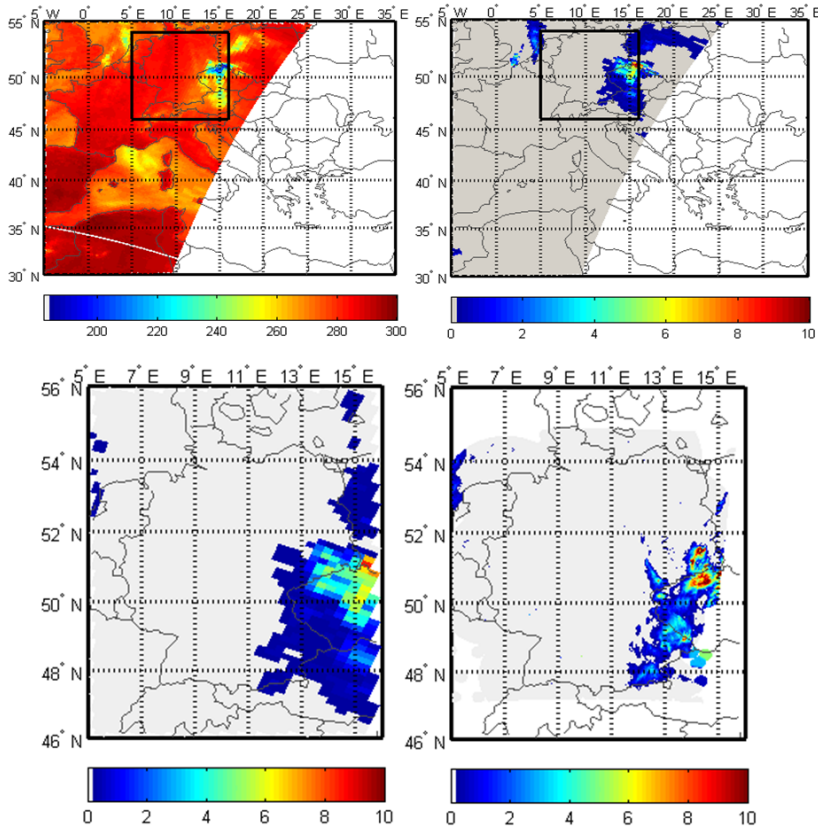

Figure 8. Convective precipitation over Germany, 7 August 2010, 09:51 UTC. Top panels: map of MHS (MetOp-A) TB (K) at $150 \mathrm{GHz}$ (left), and PNPR surface precipitation rate $\left(\mathrm{mm} \mathrm{h}^{-1}\right)$ (right) (rectangles show the approximate area covered by the radar measurements). Bottom panels: detail of radar rainfall rate estimates $\left(\mathrm{mm} \mathrm{h}^{-1}\right)$ (for the area in the rectangles shown in top panels) obtained from radar network RADOLAN, at 09:50 UTC (left), and PNPR surface precipitation rate $\left(\mathrm{mm} \mathrm{h}^{-1}\right)$ (right).

panel the TB (K) at $150 \mathrm{GHz}$ shows a slight depression in the northwest of Hungary. The pattern of the precipitation retrieved by PNPR, visible in the middle right panel of the figure, shows a noticeable ability to differentiate between the stratiform precipitation area in northwestern Hungary and the more intense, very well identified cells in correspondence to the largest TB depression. The values of the precipitation in northwestern Hungary do not exceed $3 \mathrm{~mm} \mathrm{~h}^{-1}$, while the precipitation reaches $14 \mathrm{~mm} \mathrm{~h}^{-1}$ over Bosnia and Herzegovina and the Adriatic Sea. Rectangles in the top and middle panels show the approximate area covered by the radar measurements, shown in detail in the bottom panels.

The radar estimates and precipitation pattern are quite similar to those retrieved by PNPR. The area with values of $\Delta_{17}$ larger than $-8 \mathrm{~K}$ (in the top right panel) corresponds approximately to the area where the precipitation is about $2-3 \mathrm{~mm} \mathrm{~h}^{-1}$ (bottom right panel). This result seems consistent with what was found in statistical analyses of moderate precipitation by Funatsu et al. (2009). PNPR shows a good ability in resolving precipitation signature also in the case of stratiform precipitation.

A fourth case study concerns a cyclone system formed over Hungary on 30 July 2011 that brought several thunderstorms confined to the eastern part of Hungary (the western
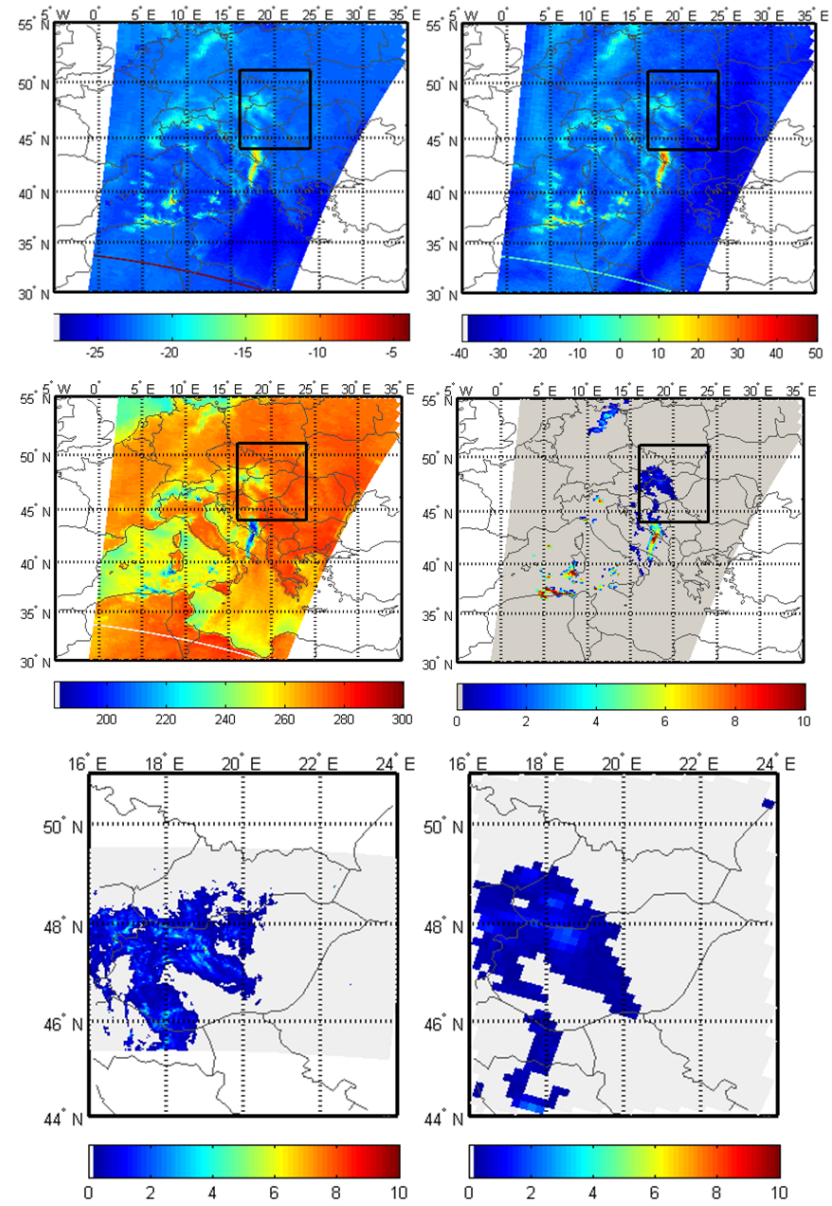

Figure 9. Stratiform precipitation over Hungary, 1 December 2009, 09:05 UTC. Top panels: map of the input data to the NN, LCT (left) and $\Delta_{17}$ (right). Middle panels: map of MHS (MetOp-A) TB (K) at $150 \mathrm{GHz}$ (left), and PNPR surface precipitation rate $\left(\mathrm{mm} \mathrm{h}^{-1}\right)$ (right) (rectangles show the approximate area covered by the radar measurements). Bottom panels: detail of radar rainfall rate estimates $\left(\mathrm{mm} \mathrm{h}^{-1}\right)$ (for the area in the rectangles shown in top panels) obtained from the Hungarian radar network, at 09:00 UTC (left), and PNPR surface precipitation rate $\left(\mathrm{mm} \mathrm{h}^{-1}\right)$ at 09:05 UTC (right).

part was not affected by precipitation). Figure 10 presents the results for this case (same as in the middle and bottom panels of Fig. 9). As in the previous cases, the ability of PNPR to correctly predict the area affected by the precipitation is remarkable. Also in this application the PNPR retrieval (bottom right panel) is in a good agreement with the radar measurements (bottom left) evidencing areas of higher precipitation in correspondence with those shown by the radar images.

\subsection{Statistical scores}

Dichotomous statistical scores and continuous statistical scores were calculated for all case studies, considering all AMSU/MHS available overpasses, and using as ground truth the closest-in-time radar rainfall estimates and/or $1 \mathrm{~h}$ cumu- 

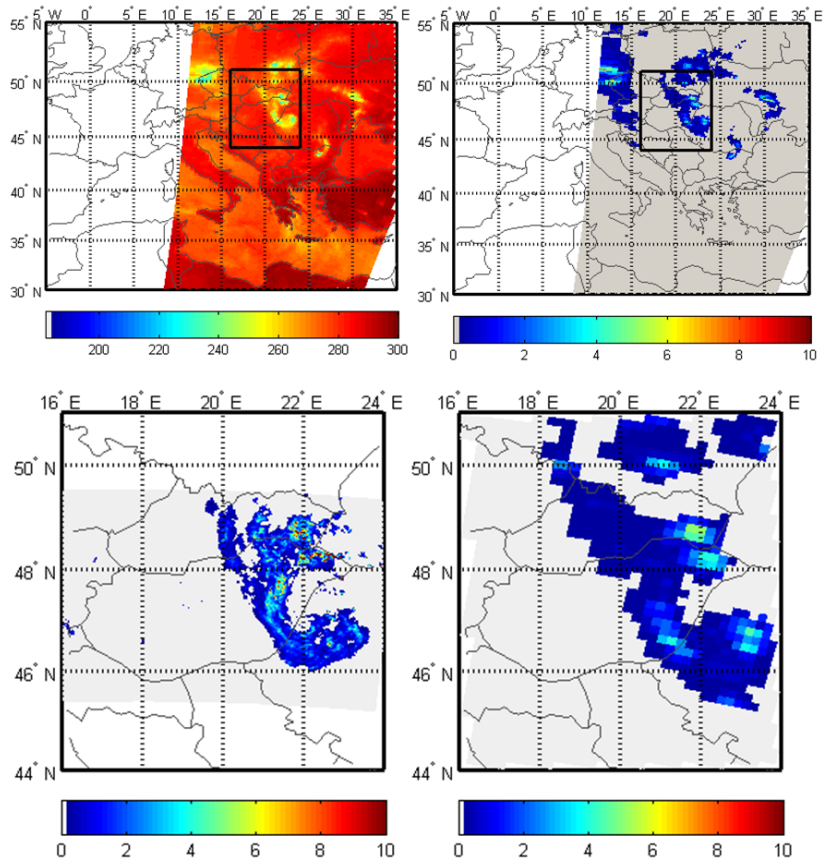

Figure 10. Thunderstorms over Hungary, 30 July 2011, 08:24 UTC. Top panels: map of MHS (MetOp-A) TB (K) at $150 \mathrm{GHz}$ (left), and PNPR surface precipitation rate $\left(\mathrm{mm} \mathrm{h}^{-1}\right)$ (right) (rectangles show the approximate area covered by the radar measurements). Bottom panels: detail of radar rainfall rate estimates $\left(\mathrm{mm} \mathrm{h}^{-1}\right.$ ) (for the area in the rectangles shown in top panels) obtained from the Hungarian radar network at 08:30 UTC (left panel), and PNPR surface precipitation rate $\left(\mathrm{mm} \mathrm{h}^{-1}\right)$ (right) at 08:24 UTC.

lated rainfall from rain gauges, spatially averaged to match the satellite IFOV horizontal resolution and orientation (see Sect. 3.1). For comparison with PNPR, the statistical scores were calculated also for the H-SAF instantaneous precipitation product H02 v2.3 (Mugnai et al., 2013a) for cross-track scanning radiometers, operational in H-SAF in the period from January 2011 throughout June 2013 (since July 2013 PNPR has become the algorithm used for the H02 H-SAF operational product (v2.4)). H02 v2.3 is based on the algorithm of Surussavadee and Staelin (2008a, b; hereafter the AMSU/MM5 algorithm), a global artificial neural-networkbased algorithm for AMSU-A/MHS (or /AMSU-B) measurements. The AMSU/MM5 algorithm is trained using a global database generated from cloud-radiation model precipitation simulations carried out at a number of locations around the globe with the Pennsylvania State UniversityNational Center for Atmospheric Research (PSU-NCAR) Mesoscale Model-5 (MM5). Within the AMSU/MM5 algorithm different NN estimators are trained for land and sea surface background. With respect to the original version of AMSU/MM5, in H02 v2.3 a calibration procedure was adopted to optimize the retrieval for the European/Mediterranean area (whereas in PNPR no calibration is carried out, while the training cloud-radiation data set was specifically created to represent the Europe/Mediterranean area). The H02 v2.3 calibration was carried out using the ground-based data from the H-SAF rain gauge and radar network, with different procedures depending on latitude (lat $\leq 45^{\circ} \mathrm{N}, 45^{\circ} \mathrm{N}<$ lat $<50^{\circ} \mathrm{N}$, lat $\geq 50^{\circ} \mathrm{N}$ ) and season. $\mathrm{H} 02 \mathrm{v} 2.3$ has the same screening procedure (for identification of potentially precipitating pixels) used in PNPR. Moreover, H02 v2.3 uses a specific neural network to process the radiometer brightness temperatures in order to correct the limb effect. The H-SAF product $\mathrm{H} 02$ v2.3 is being routinely validated, for the whole period of operation, through extensive validation over Europe carried out by the H-SAF PPVG (Puca et al., 2014).

We have used the H02 v2.3 algorithm for the retrieval of precipitation in the four case studies analyzed in the previous section, utilizing the same overpasses and same TBs (AMSU-A and MHS level 1c input data) as in PNPR. Figure 11 shows the results obtained from H02 v2.3 for three of the four overpasses presented in the previous section (the stratiform precipitation case in Hungary of 1 December 2009 is not shown because the results obtained with the two algorithms are very similar). In the figure, the $\mathrm{H} 02$ v2.3 retrievals are presented in the left panels, and the ground-based measurements in the right panels (rain gauges in the top panel for the Italy case, and high-resolution radar estimates in the middle and bottom panels for the Germany and Hungary cases). By comparing these results with those obtained with PNPR - shown in Figs. 7, 8, and 10 - a good agreement is evident of the precipitation pattern between the two algorithms, with significantly improved ability of PNPR to localize the areas affected by heavy precipitation. In the 25 October 2011 case (Italy) the precipitation in $\mathrm{H} 02 \mathrm{v} 2.3$ is highly underestimated along the coast of Liguria. A significant underestimation of the most intense precipitation (both with respect to the ground-based data and with respect to PNPR) is also evident for the Germany case (7 August 2010, panels in the middle of Fig. 11) and for the Hungary case of scattered thunderstorms (30 July 2011, bottom panels in Fig. 11).

Table 3 presents the statistical scores (defined according to Nurmi (2003) and used in Puca et al. (2014)) of H02 v2.3 and PNPR retrievals compared to ground measurements (gauges or radars), calculated for all available satellite overpasses for all case studies (Table 4 provides a list of all overpasses available). The continuous statistical scores (to verify the accuracy of rainfall rate estimation) are mean error (ME), standard deviation (SD), the root mean squared error (RMSE) and the correlation coefficient (CC). The dichotomous statistical scores (to verify the accuracy of rain detection) are probability of detection (POD), false alarm rate (FAR) and critical success index (CSI) where the rain/no rain threshold was set to $0.25 \mathrm{~mm} \mathrm{~h}^{-1}$. POD90, FAR90 and CSI90 represent the values of POD, FAR and CSI limited to precipitation values above the 90th percentile of the three convective cases. These indexes were introduced to evaluate the algorithm's ability to correctly identify the location of the areas of heavy precipi- 

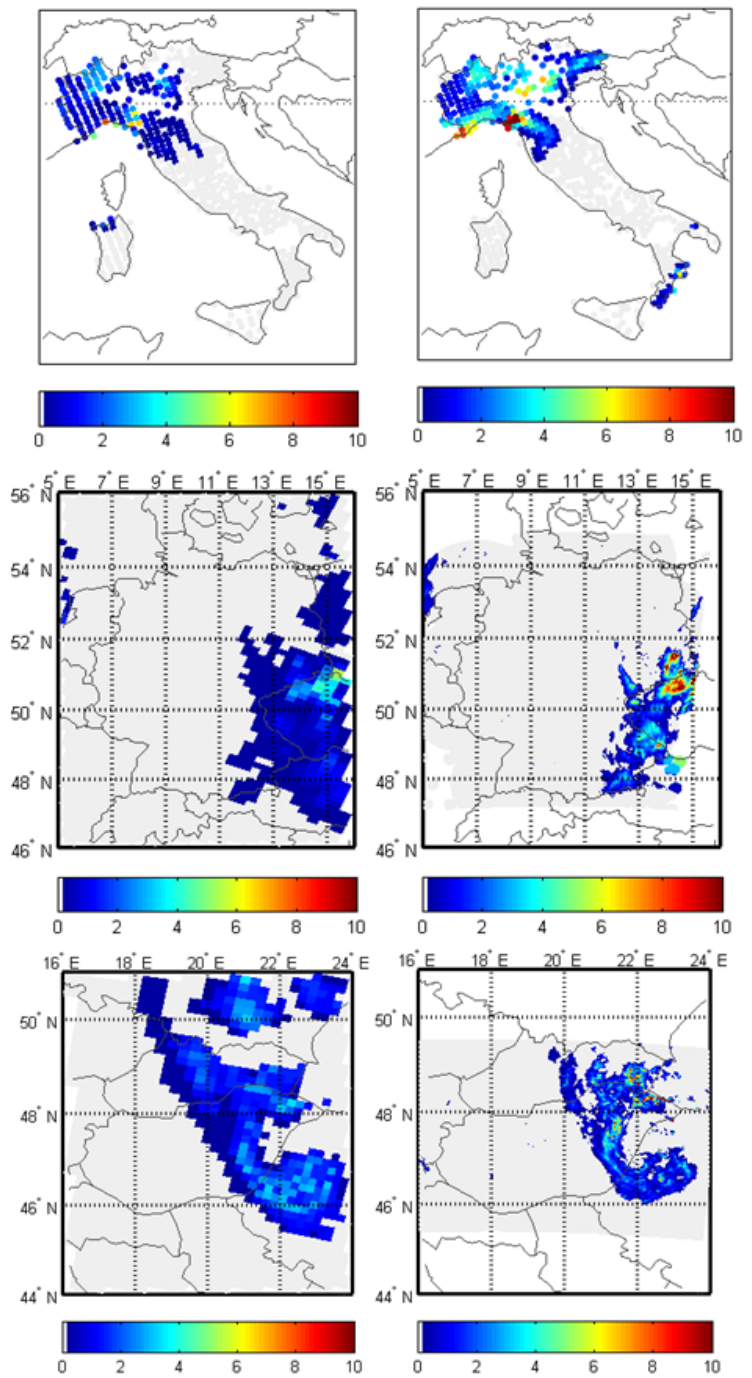

Figure 11. Comparison between H-SAF product H02 v2.3 (left panels) and ground-based measurements (right panels). Top panels: flood over the La Spezia area (Italy, $44^{\circ} \mathrm{N}, 10^{\circ} \mathrm{E}$ ), 25 October 2011, 11:44 UTC. H02 v2.3 surface precipitation rate $\left(\mathrm{mm} \mathrm{h}^{-1}\right)$ over land (left), and $1 \mathrm{~h}$ cumulated precipitation (11:00-12:00 UTC) from rain gauges, spatially averaged and sampled (right). Middle panels: convective precipitation over Germany, 7 August 2010, 09:51 UTC. H02 v2.3 surface precipitation rate $\left(\mathrm{mm} \mathrm{h}^{-1}\right)$ (left), and radar rainfall rate estimate $\left(\mathrm{mm} \mathrm{h}^{-1}\right)$ at high resolution at 09:50 UTC (right). Bottom panels: thunderstorms over Hungary, 30 July 2011, 08:30 UTC. H02 v2.3 surface precipitation rate $\left(\mathrm{mm} \mathrm{h}^{-1}\right)$ (left) at 08:24 UTC, and radar rainfall rate estimate $\left(\mathrm{mm} \mathrm{h}^{-1}\right)$ at high resolution at 08:30 UTC (right).

tation, often associated with convection. The improvement is evident of PNPR with respect to H02 v2.3 both in the continuous and the dichotomous statistics scores. It is remarkable that the PNPR precipitation product is not subject to any kind of calibration, and the results derive uniquely from the high quality of the training database used, representative of the
Table 3. Cumulative error statistics of $\mathrm{H} 02$ v 2.3 and PNPR retrievals for all available satellite overpasses for all case studies.

\begin{tabular}{lrr}
\hline & H02 v2.3 & PNPR \\
\hline ME & -1.07 & -0.75 \\
SD & 2.90 & 2.47 \\
RMSE & 2.22 & 2.10 \\
CC & 0.50 & 0.63 \\
POD & 0.74 & 0.74 \\
FAR & 0.43 & 0.40 \\
CSI & 0.48 & 0.52 \\
POD90 & 0.54 & 0.63 \\
FAR90 & 0.46 & 0.39 \\
CSI90 & 0.37 & 0.41 \\
\hline
\end{tabular}

Table 4. Satellite overpasses (UTC times) utilized in the binned analysis.

\begin{tabular}{lll}
\hline Country & Date & Satellite overpass time (UTC) \\
\hline Italy & 25 October 2011 & $01: 27,02: 03,03: 08,08: 26$, \\
& & $10: 06,11: 50,12: 54,19: 49$ \\
Germany & 7 August 2010 & $00: 18,02: 00,02: 01,09: 50$, \\
& & $11: 50,11: 52,13: 35,19: 38$ \\
Hungary & 1 December 2009 & $00: 50,01: 13,09: 05,11: 02$, \\
& & $12: 20,12: 43,18: 50,20: 30$ \\
Hungary & \multirow{2}{*}{ 30 July 2011 } & $00: 27,01: 59,08: 24,10: 04$, \\
& & $11: 48,11: 57,13: 29,19: 50$
\end{tabular}

European/Mediterranean climatology, and on the design of the $\mathrm{NN}$ and of the algorithm.

A further verification of the results obtained in the case studies was performed using the binned analysis introduced by Ferraro and Marks (1995) and employed in verification studies of satellite-based precipitation retrieval using groundbased measurements (e.g., Di Tommaso et al., 2009). Following this approach the ground-based data (radar or rain gauges) averaged at the satellite IFOV resolution were separated in $1 \mathrm{~mm} \mathrm{~h}^{-1}$ rain rate bins, and the mean of the corresponding retrieved rainfall rate values from PNPR and H02 v2.3 was computed for each bin. The last bin represents all pixels with a precipitation rate above $10 \mathrm{~mm} \mathrm{~h}^{-1}$. The use of this technique allows comparing quantitatively the results in separate intervals over the full range of rain rate values. In addition it allows mitigating, to some extent, the negative effect of time-space mismatches on the comparison between the satellite retrieval and the ground-based measurements. Figure 12 shows the result of this analysis. The data used refer to all satellite overpasses for each of the four case studies. Table 4 shows the times of the satellite overpasses utilized.

In Fig. 12, the left panel shows the mean retrieved values of PNPR and H02 v2.3 plotted against the corresponding ground-based measurements in each $1 \mathrm{~mm} \mathrm{~h}^{-1}$ rain rate bin. From the figure is evident that there is a good correlation between PNPR and ground-based measurements, with 

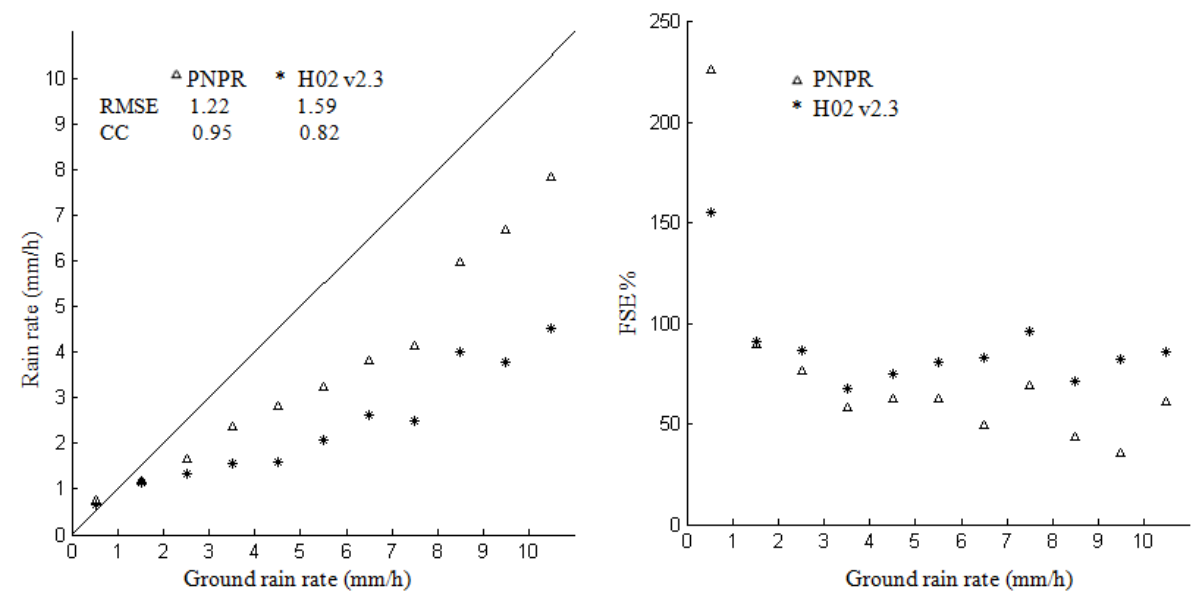

Figure 12. Binned analysis of PNPR and H02 v2.3 retrievals for all case studies. The left panel shows the average retrieved values as a function of the $1 \mathrm{~mm} \mathrm{~h}^{-1}$ rain rate bins of ground-based measurements. The right panel shows the FSE\% values obtained for the retrievals within each bin (see the text for details).

a general underestimation by PNPR when the values of the precipitation rate are larger than $2 \mathrm{~mm} \mathrm{~h}^{-1}$. The correlation is lower for $\mathrm{H} 02 \mathrm{v} 2.3$, and the underestimation is much more evident. The panel also shows the values of the statistical indexes RMSE and CC obtained by comparing the mean values of the retrievals (PNPR and H02) with the corresponding mean values of the ground-based measurements.

In the right panel of Fig. 12 the values of the fractional standard error percentage (FSE\%), obtained for the retrievals within each bin, are shown. FSE\% is defined as

$\mathrm{FSE} \%=100 \cdot \frac{\mathrm{rmse}}{\overline{\text { true }}}$,

where true is the mean value of the ground-based measurements in each bin. The values of this statistical index also confirm a better performance of PNPR compared to H02 v2.3 for all rain rate bins (FSE\% between 40 and $60 \%$ for most bins) except in the first bin (FSE\% higher for PNPR than $\mathrm{H} 02$ v2.3) and for the second bin (FSE\% around $90 \%$ for both algorithms). The result obtained for the first bin is due to the algorithms' uncertainties in detecting very low precipitation rates, mitigated in the $\mathrm{H} 02$ v 2.3 algorithm by the calibration procedure, more efficient for low rain rate values.

\section{Summary and conclusions}

The design, the characteristics and the performance of a new algorithm (PNPR) for surface precipitation estimation from cross-track passive microwave radiometers based on a single neural network for all types of surface background have been presented. The algorithm was trained using a database based on cloud-resolving model simulations, optimized for the European and Mediterranean Basin areas. It receives as input a linear combination of TBs of the window channels 50.3, 89 and $150 \mathrm{GHz}$ and the differences of TBs of the $183.31 \mathrm{GHz}$ water vapor absorption band (in addition to some ancillary environmental data). These TB differences have been proven to be very effective in detecting precipitation, differentiating between different precipitation structures and in the retrieval of rainfall rate. The algorithm provides in output, in addition to the precipitation, the phase and a quality index that provide a simple and immediate criterion for the evaluation of the retrieval reliability.

Applied to four different weather conditions in Europe, the algorithm has shown good performance both in the identification of precipitation areas and in the retrieval of precipitation. The use of a single NN has responded correctly at transitions between land, coast and sea, without introducing discontinuities in the precipitation estimates. The precipitation pattern and intensity agree well with those of the ground data. In particular, the NN estimations were particularly efficient in the identification of heavy-rain areas of convective events. The correct identification of the precipitation pattern in the case of light rain was also evidenced, but it also showed some criticisms, due to fact that in some conditions the microwave signal corresponding to rainy pixels is very weak, and it is often difficult to be discriminated from rain-free pixels. Moreover, as highlighted by the low values of the percentage confidence index, other critical cases are represented by very cold/dry environmental situations, snowy/iced backgrounds and over the coastal areas. The quality index higher for convective precipitation or in warm/moist environmental conditions, and lower for light stratiform precipitation and/or cold/dry conditions, or in the presence of a snowy/iced background - indicates the reliability or the criticisms linked to the retrieval. The phase flag is evaluated only for pixels flagged as precipitating after the screening procedure and is not available over coastal background surfaces (examples of phase determination results, for liquid, snow and ice precipitation, are shown in Panegrossi et. al., 2013). The comparison 
with the H-SAF H02 v2.3 algorithm (operational until June 2013), although limited to four cases, showed a good performance of PNPR and better agreement with the ground-based precipitation data. It should be mentioned that a more extensive verification study (19 case studies selected from the H-SAF PPVG reports for the period 2009-2011) has been carried out (Panegrossi et al., 2013) and the results are in line with what is shown here, and with what has been obtained in the comparison with the H-SAF H02 v2.3. PNPR shows improved ability in the screening and retrieval of precipitation over different background surfaces, in the identification and retrieval of heavy rain for convective events and, in some cases, in the identification of precipitation over a cold/iced background. Moreover, these results are also confirmed by the validation of PNPR over the African area over a 2 yr period (2011-2012) where we use the TRMM precipitation radar (PR) precipitation products as "truth" (presented in Panegrossi et al., 2014).

In particular, the PNPR algorithm has shown better results in the localization of the heavy-precipitation areas. These results were confirmed by better statistical scores (both dichotomous and continuous) for all case studies analyzed and, in particular, for the areas characterized by heavy precipitation. It should be mentioned that while $\mathrm{H} 02$ v2.3 retains the characteristics of AMSU/MM5, designed for a global precipitation retrieval and it has been calibrated to be optimized for the European and Mediterranean areas, the optimization of PNPR algorithm for the European region uniquely stems from physical assumption, i.e., in the construction of the cloud-radiation database used in the training phase of the retrieval. Moreover, the input variables used in PNPR are different from those used in $\mathrm{H} 02$ v2.3 and allow for the use of a unique $\mathrm{NN}$ for all types of background surfaces.

It is worth noting that PNPR has been developed with the aim to obtain precipitation retrievals from cross-track scanning radiometers as consistent as possible with those obtained from conically scanning radiometers, optimized for the European/Mediterranean Basin region. This consistency, besides the accuracy of the retrievals, is necessary in order to be able to fully exploit all cross-track and conical scanning radiometer overpasses from the GPM constellation of satellites (available at about $3 \mathrm{~h}$ time interval in most parts of the globe) and to be able to use precipitation products derived from all sensors for monitoring precipitation at higher spatial/temporal resolution (i.e., through blending or morphing techniques with IR observations from geostationary satellites). The full exploitation of all available sensors will provide also useful products for nowcasting and/or hydrological applications, with a significant reduction of the errors associated with the inadequate sampling of precipitation. The PNPR is a highly adaptable algorithm to different environmental conditions, and it is computationally very efficient. Since July 2013, it has become the algorithm for the operational instantaneous precipitation product from crosstrack PMW radiometers within the EUMETSAT H-SAF for
Europe and the Mediterranean Basin area (H-SAF product H02 ver.2.4). All data are sent to EUMETSAT to be broadcast by EUMETCast in near-real time. Off-line products are available via the EUMETSAT Data Center and the website http://hsaf.meteoam.it. Similarly to all H-SAF operational and pre-operational products, PNPR used in H-SAF will soon undergo the standard independent validation carried out routinely by the H-SAF PPVT team, which will further contribute to outlining the strengths and the limitations of PNPR with particular attention to case studies around arid regions, and at high latitudes in cold/conditions, experiencing light rain or snowfall.

The algorithm has recently undergone further development with extension to the MSG full disk area. This new algorithm uses a new neural network to estimate the surface precipitation over the African region and a new screening procedure (Casella et al. 2014) to identify the presence of precipitation over arid surfaces. In a paper in preparation, we will show the results of the validation of the extended version of the algorithm over Africa and the South Atlantic, where two full years (2011 and 2012) of coincident overpasses of AMSU/MHS and the PR aboard the TRMM space observatory are used. The use of PR has the advantage of providing consistent estimates of precipitation over an extended period of time and over different regions in the tropics (between $35^{\circ} \mathrm{S}$ and $35^{\circ} \mathrm{N}$ ). In the future, with the use of the Dual-frequency Precipitation Radar (DPR) aboard GPM, it will be possible to apply a similar validation procedure of all H-SAF MSG full disk products, exploiting also the information of the 3-D microphysical structure of the precipitating cloud. Finally, PNPR has the feature of being easily adaptable to other cross-rack scanning radiometers, such as the ATMS aboard the Suomi NPP satellite, for which a different version of PNPR is under development.

Acknowledgements. The authors would like to thank the members of the H-SAF Precipitation Product Validation Group for providing the radar and rain gauge data used for the case studies, and the National Oceanic and Atmospheric Administration (NOAA, http://www.class.ngdc.noaa.gov) for providing the AMSU-A/MHS radiometer data. The authors also thank the anonymous reviewers for the useful recommendations. This research was supported by EUMETSAT through the project "Satellite Application Facility on Support to Operational Hydrology and Water Management" (H-SAF) and by the Italian Civil Protection Department.

Edited by: M. Kulie 


\section{References}

Anagnostou, E. N. and Krajewski, W. F.: Real-time radar rainfall estimation. Part I: Algorithm formulation, J. Atmos. Ocean. Tech., 16, 189-197, 1999.

Anders, U. and Korn, O.: Model selection in neural networks, Neural Netw., 12, 309-323, 1999.

Bauer, P., Moreau, E., and Di Michele, S.: Hydrometeor retrieval accuracy using microwave window and sounding channel observations, J. Appl. Meteorol., 44, 1016-1032, doi:10.1175/JAM2257.1, 2005.

Bellerby, T. J.: Satellite rainfall uncertainty estimation using an artificial neural network, J. Hydrometeorol., 8, 1397-1412, 2007.

Bennartz, R. and Bauer, P.: Sensitivity of microwave radiances at $85-183 \mathrm{GHz}$ to precipitating ice particles, Radio Sci., 38, 8075, doi:10.1029/2002RS002626, 2003.

Bennartz, R. and Petty, G. W.: The sensitivity of microwave remote sensing observations of precipitation to ice particle size distributions, J. Appl. Meteorol., 40, 345-364, 2001.

Blackwell, W. J. and Chen, F. W.: Neural network applications in high-resolution atmospheric remote sensing, Lincoln Lab. J., 15, 299-322, 2005.

Burns, B. A., Wu, X., and Diak, G. R.: Effects of precipitation and cloud ice on brightness temperatures in AMSU moisture channels, IEEE T. Geosci. Remote, 35, 1429-1437, 1997.

Casella, D., Dietrich, S., Formenton, M., Mugnai, A., Panegrossi, G., Sanò, P., Smith, E. A., and Tripoli G. J.: Verification of Cloud Dynamics and Radiation Database (CDRD) passive microwave precipitation retrieval algorithm using TRMM satellite radar and radiometer measurements over Southern Mediterranean Basin, Microwave Radiometry and Remote Sensing of the Environment (MicroRad), 2012 12th Specialist Meeting, 1-4, 2012.

Casella, D., Panegrossi, G., Sanò, P., Mugnai, A., Smith, E. A., Tripoli, G. J., Dietrich, S., Formenton, M., Leung, W. Y., and Mehta, A.: Transitioning from CRD to CDRD in bayesian retrieval of rainfall from satellite passive microwave measurements: Part 2. Overcoming database profile selection ambiguity by consideration of meteorological control on microphysics, IEEE T. Geosci. Remote, 51, 4650-4671, 2013.

Casella, D., Panegrossi, G., Sanò, P., Milani, L., Petracca, M., and Dietrich, S.: A novel algorithm for detection of precipitation in tropical regions using PMW radiometers, Atmos. Meas. Tech. Discuss., 7, 9237-9274, doi:10.5194/amtd-7-9237-2014, 2014.

Chen, F. W. and Staelin, D. H.: AIRS/AMSU/HSB precipitation estimates, IEEE T. Geosci. Remote, 41, 410-417, 2003.

Chen, Y., Aires, F., Francis, J. A., and Miller, J. R.: Observed relationships between artic longwave cloud forcing and cloud parameters using a neural network, J. Climate, 19, 4087-4104, 2006.

Deeter, M. N. and Vivekanandan, J.: AMSU-B Observations of mixed-phase clouds over land, J. Appl. Meteorol., 44, 72-85, 2005.

Di Tommaso, E., Romano, F., and Cuomo, V.: Rainfall estimation from satellite passive microwave observations in the range $89 \mathrm{GHz}$ to $190 \mathrm{GHz}$, J. Geophys. Res., 114, D18203, doi:10.1029/2009JD011746, 2009.

Ferraro, R. R.: The Status of the NOAA/NESDIS Operational AMSU Precipitation Algorithm, 2nd Workshop of the International Precipitation Working Group, Monterey, 9 pp., 2004.
Ferraro, R. R. and Marks, G. F.: The development of SSM/I rain-rate retrieval algorithms using ground-based radar measurements, J. Atmos. Ocean. Tech., 12, 755-770, 1995.

Ferraro, R. R., Smith, E. A., Berg, W., and Huffman, G. J.: A screening methodology for passive microwave precipitation retrieval algorithms, J. Atmos. Sci., 55, 1583-1600, 1998.

Ferraro, R. R., Weng, F., Grody, N. C., and Zhao, L.: Precipitation characteristics over land from the NOAA-15 AMSU sensor, Geophys. Res. Lett., 27, 2669-2672, 2000.

Ferraro, R. R., Weng, F., Grody, N. C., Zhao, L., Meng, H., Kongoli, C., Pellegrino, P., Qiu, S., and Dean, C.: NOAA operational hydrological products derived from the advanced microwave sounding unit, IEEE T. Geosci. Remote, 43, 1036-1049, 2005.

Funatsu, B. M., Claud, C., and Chaboureau, J.-P.: Potential of Advanced Microwave Sounding Unit to identify precipitating systems and associated upper-level features in the Mediterranean region: case studies, J. Geophys. Res., 112, D17113, doi:10.1029/2006JD008297, 2007.

Funatsu, B. M., Claud, C., and Chaboureau, J.-P.: Comparison between the large-scale environments of moderate and intense precipitating systems in the Mediterranean region, Mon. Weather Rev., 137, 3933-3959, 2009.

Funatsu, B. M., Dubreuil, V., Claud, C., Arvor, D., and Gan, M. A.: Convective activity in Mato Grosso state (Brazil) from microwave satellite observations: comparisons between AMSU and TRMM data sets, J. Geophys. Res., 117, D16109, doi:10.1029/2011JD017259, 2012.

Goldberg, M. D., Crosby, D. S., and Zhou, L.: The limb adjustment of AMSU-A observations: methodology and validation, J. Appl. Meteorol., 40, 70-83, 2001.

Greenwald, T. J. and Christopher, S. A.: Effect of cold clouds on satellite measurements near $183 \mathrm{GHz}$, J. Geophys. Res.-Atmos., 107, AAC 3/1-AAC 3/8, 2002.

Grody, N., Weng, F., and Ferraro, R.: Application of AMSU for obtaining hydrological parameters, in: Microwave Radiometry and Remote Sensing of the Earth's Surface and Atmosphere, edited by: Pampaloni, P. and Paloscia, S., VSP, 339-352, 2000.

Hair, J. F., Tatham, R. L., Anderson, R. E., and Black, W.: Multivariate Data Analysis, 5th Edition, Prentice Hall, Inc., ISBN-13: 978-0138948580, 1998.

Hall, T., Brooks, H. E., and Doswell III, C. A., Precipitation forecasting using a neural network, Weather Forecast., 14, 338-345, 1999.

Hong, G., Heygster, G., Miao, J., and Kunzl, K.: Detection of tropical deep convective clouds from AMSU-B vater vapor channels measurements, J. Geophys. Res., 110, D05205, doi:10.1029/2004JD004949, 2005.

Hong, Y., Hsu, K.-L., Sorooshian, S., and Gao, X.: Precipitation estimation from remotely sensed imagery using an artificial neural network cloud classification system, J. Appl. Meteorol., 43, 1834-1853, 2004.

Hou, A. Y., Kakar, R. K., Neeck, S., Azarbarzin, A. A., Kummerow, C. D., Kojima, M., Oki, R., Nakamura, K., and Iguchi, T.: The global precipitation measurement mission, B. Am. Meteorol. Soc., 95, 701-722, doi:10.1175/BAMS-D-13-00164.1, 2014.

Hsu, K.-L., Gao, X., Sorooshian, S., and Gupta, H. V.: Precipitation estimation from remotely sensed information using artificial neural networks, J. Appl. Meteorol., 36, 1176-1190, 1997. 
Johnson, B. T., Petty, G. W., and Skofronick-Jackson, G.: Microwave properties of ice-phase hydrometeors for radar and radiometers: sensitivity to model assumptions, J. Appl. Meteorol. Climatol., 51, 2152-2171, doi:10.1175/JAMC-D-11-0138.1, 2012.

Jolliffe, I. T.: Principal Component Analysis, 2nd Edition, Springer Series in Statistics, ISBN-13: 978-0387954424, 2002.

Kongoli, C., Pellegrino, P., Ferraro, R. R., Grody, N. C., and Meng, H.: A new snowfall detection algorithm over land using measurements from the Advanced Microwave Sounding Unit (AMSU), Geophys. Res. Lett., 30, L1756, doi:10.1029/2003GL017177, 2003.

Kongoli, C., Ferraro, R. R., Pellegrino, P., Meng, H., and Dean, C.: Utilization of the AMSU high frequency measurements for improved coastal rain retrievals, Geophys. Res. Lett., 34, L17809, doi:10.1029/2007GL029940, 2007.

Krasnopolsky, V. M., Fox-Rabinovitz, M. S., and Belochitski, A. A.: Decadal climate simulations using accurate and fast neural network emulation of full, longwave and shortwave, radiation, Mon. Weather Rev., 136, 3683-3695, doi:10.1175/2008MWR2385.1, 2008.

Kulie, M. S., Bennartz, R., Greenwald, T. J., Chen, Y., and Weng, F.: Uncertainties in microwave properties of frozen precipitation: implications for remote sensing and data assimilation, J. Atmos. Sci., 67, 3471-3487, doi:10.1175/2010JAS3520.1, 2010.

Kummerow, C., Simpson, J., Thiele, O., Barnes, W., Chang, A. T. C., Stocker, E., Adler, R. F., Hou, A., Kakar, R., Wentz, F., Ashcroft, P., Kozu, T., Hong, Y., Okamoto, K., Iguchi, T., Kuroiwa, H., Im, E., Haddad, Z., Huffman, G., Ferrier, B., Olson, W. S., Zipser, E., Smith, E. A., Wilheit, T. T., North, G., Krishnamurti, T., and Nakamura, K.: The Status of the tropical rainfall measuring mission (TRMM) after two years in orbit, $\mathrm{J}$. Appl. Meteorol., 39, 1965-1982, 2000.

Kummerow, C., Hong, Y., Olson, W. S., Yang, S., Adler, R. F., McCollum, J., Ferraro, R., Petty, G., Shin, D. B., and Wilheit, T. T.: The evolution of the Goddard profiling algorithm (GPROF) for rainfall estimation from passive microwave sensors, J. Appl. Meteorol., 40, 1801-1820, 2001.

Laviola S. and Levizzani, V.: The 183-WLS fast rain rate retrieval algorithm. Part I: Retrieval design, Atmos. Res., 99, 443-461, 2011.

Leslie, R. V., Blackwell, W. J., Bickmeier, L. J., and Jaram, L. G.: Neural network microwave precipitation retrievals and modeling results, Proc. SPIE, 7154, 715406-8, doi:10.1117/12.804815, 2008.

Lin X. and Hou, A. Y.: Evaluation of coincident passive microwave estimates using TRRM PR and ground measurements as references, J. Appl. Meteorol. Climatol., 47, 3170-3187, 2008.

Marzano, F. S., Mugnai, A., Panegrossi, G., Pierdicca, N., Smith, E. A., and Turk, J.: Bayesian estimation of precipitating cloud parameters from combined measurements of spaceborne microwave radiometer and radar, IEEE T. Geosci. Remote, 37, 596612,1999

Marzban C.: Basic statistics and basic AI: neural networks, in: Artificial Intelligence Methods in the Environmental Science, edited by: Haupt, S. E., Pasini, A., and Marzban, C., Springer, 15-47, 2009.

Mugnai, A., Cooper, H. J., Smith, E. A., and Tripoli, G. J.: Simulation of microwave brightness temperatures of an evolving hail- storm at SSM/I frequencies, B. Am. Meteorol. Soc., 71, 2-13, 1990.

Mugnai, A., Smith, E. A., and Tripoli, G. J.: Foundations for statistical physical precipitation retrieval from passive microwave satellite measurement. Part II : Emission-source and generalized weighting-function properties of a time-dependent cloudradiation model, J. Appl. Meteorol, 32, 17-39, 1993.

Mugnai, A., Di Michele, S., Marzano, F. S., and Tassa, A.: Cloud-model based Bayesian techniques for precipitation profile retrieval from TRMM microwave sensors, Proc. ECMWF/EuroTRMM Workshop on Assimilation of Clouds and Precipitation, ECMWF, Reading, UK, 323-345, 2001.

Mugnai, A., Casella, D., Cattani, E., Dietrich, S., Laviola, S., Levizzani, V., Panegrossi, G., Petracca, M., Sanò, P., Di Paola, F., Biron, D., De Leonibus, L., Melfi, D., Rosci, P., Vocino, A., Zauli, F., Pagliara, P., Puca, S., Rinollo, A., Milani, L., Porcù, F., and Gattari, F.: Precipitation products from the hydrology SAF, Nat. Hazards Earth Syst. Sci., 13, 1959-1981, doi:10.5194/nhess-13-1959-2013, $2013 \mathrm{a}$.

Mugnai, A., Smith, E. A., Tripoli, G. J., Bizzarri, B., Casella, D., Dietrich, S., Di Paola, F., Panegrossi, G., and Sanò, P.: CDRD and PNPR satellite passive microwave precipitation retrieval algorithms: EuroTRMM/EURAINSAT origins and $\mathrm{H}-$ SAF operations, Nat. Hazards Earth Syst. Sci., 13, 887-912, doi:10.5194/nhess-13-887-2013, 2013b.

Nurmi, P.: Recommendations on the verification of local weather forecasts, 11 ECMWF Tech. Memo. N. 430, 19 pp., 2003.

Panegrossi, G., Dietrich, S., Marzano, F. S., Mugnai, A., Smith, E. A., Xiang, X., Tripoli, G. J., Wang, P. K., and Poiares Baptista, J. V. P.: Use of cloud model microphysics for passive microwavebased precipitation retrieval: significance of consistency between model and measurement manifolds, J. Atmos. Sci., 55, 1644 1673, 1998.

Panegrossi, G., Casella, D., Dietrich, S., Sanò, P., Petracca, M., and Mugnai, A.: A verification study over Europe of AMSU/MHS and SSMIS passive microwave precipitation retrieval, Proc. 2013 Joint EUMETSAT/AMS Meteorological Satellite Conference, 8 pp., 2013.

Panegrossi, G., Casella, D., Dietrich, S., Marra, A. C., Milani, L., Petracca, M., Sanò, P., and Mugnai, A.: CDRD and PNPR passive microwave precipitation retrieval algorithms: extension to the MSG full disk area, Proc. 2014 EUMETSAT Meteorological Satellite Conference, Geneva, https://www.eumetsat.int/website/ home/News/ConferencesandEvents/DAT_2076129.html, last access: 18 February 2014.

Porcù, F., Milani, L., and Petracca, M.: On the uncertainties in validating satellite instantaneous rainfall estimates with raingauge operational network, Atmos. Res., 144, 73-81, doi:10.1016/j.atmosres.2013.12.007, 2014.

Puca, S., Porcu, F., Rinollo, A., Vulpiani, G., Baguis, P., Balabanova, S., Campione, E., Ertürk, A., Gabellani, S., Iwanski, R., Jurašek, M., Kaňák, J., Kerényi, J., Koshinchanov, G., Kozinarova, G., Krahe, P., Lapeta, B., Lábó, E., Milani, L., Okon, L'., Öztopal, A., Pagliara, P., Pignone, F., Rachimow, C., Rebora, N., Roulin, E., Sönmez, I., Toniazzo, A., Biron, D., Casella, D., Cattani, E., Dietrich, S., Di Paola, F., Laviola, S., Levizzani, V., Melfi, D., Mugnai, A., Panegrossi, G., Petracca, M., Sanò, P., Zauli, F., Rosci, P., De Leonibus, L., Agosta, E., and Gattari, F.: The validation service of the hydrological SAF geostationary and po- 
lar satellite precipitation products, Nat. Hazards Earth Syst. Sci., 14, 871-889, doi:10.5194/nhess-14-871-2014, 2014.

Qiu, S., Pellegrino, P., Ferraro, R., and Zhao, L.: The improved AMSU rain-rate algorithm and its evaluation for a cool season event in the Western United States, Weather Forecast., 20, 761$774,2005$.

Rachimow, C. and Krahe, P.: Validation report for H-SAF product H01 (PR-OBS-1, precipitation rate at ground) in Germany, Federal Institute of Hydrology (BfG), Koblenz, p. 16, 2011.

Rebora, N., Molini, L., Casella, E., Comellas, A., Fiori, E., Pignone, F., Siccardi, F., Silvestro, F., Tanelli, S., and Parodi, A.: Extreme rainfall in the Mediterranean: what can we learn from observations?, J. Hydrometeorol., 14, 906-922, doi:10.1175/JHM-D-12083.1, 2013.

Rinollo, A., Vulpiani, G., Puca, S., Pagliara, P., Kaňák, J., Lábó, E., Okon, L'., Roulin, E., Baguis, P., Cattani, E., Laviola, S., and Levizzani, V.: Definition and impact of a quality index for radar-based reference measurements in the H-SAF precipitation product validation, Nat. Hazards Earth Syst. Sci., 13, 2695-2705, doi:10.5194/nhess-13-2695-2013, 2013.

Rosenkranz, P. W.: Rapid radiative transfer model for AMSU/HSB channels, IEEE T. Geosci. Remote, 41, 362-368, 2003.

Sanò, P., Casella, D., Mugnai, A., Schiavon, G., Smith, E. A., and Tripoli, G. J.: Transitioning from CRD to CDRD in bayesian retrieval of rainfall from satellite passive microwave measurements: Part 1. Algorithm description and testing, IEEE T. Geosci. Remote, 51, 4119-4143, 2013.

Shi, L.: Retrieval of atmospheric temperature profiles from AMSUA measurement using a neural network approach, J. Atmos. Ocean. Tech., 18, 340-347, 2001.

Skofronick-Jackson, G. and Johnson, B. T.: Surface and atmospheric contributions to passive microwave brightness temperatures for falling snow events, J. Geophys. Res., 116, D02213, doi:10.1029/2010JD014438, 2011.

Skofronick-Jackson, G. M., Johnson, B. T., and Munchak, S. J.: Detection thresholds of falling snow from satellite-borne active and passive sensors, IEEE T. Geosci. Remote, 51, 4177-4189, doi:10.1109/TGRS.2012.2227763, 2013.

Smith, E. A., Lamm, J. E, Adler, R., Alishouse, J., Aonashi, K., Barrett, E., Bauer, P., Berg, W., Chang, A., Ferraro, R., Ferriday, J., Goodman, S., Grody, N., Kidd, C., Kniveton, D., Kummerow, C., Liu, G., Marzano, F. S., Mugnai, A., Olson, W., Petty, G., Shibata, A., Spencer, R., Wentz, F., Wilheit, T., and Zipser, E.: Results of WetNet PIP-2 project, J. Atmos. Sci., 55, 1483-1536, 1998.

Smith, E. A., Bauer, P., Marzano, F. S., Kummerow, C. D., McKague, D., Mugnai, A., and Panegrossi, G.: Intercomparison of microwave radiative transfer models for precipitating clouds, IEEE T. Geosci. Remote, 40, 541-549, 2002.

Smith, E. A., Leung, H. W.-Y., Elsner, J. B., Mehta, A. V., Tripoli, G. J., Casella, D., Dietrich, S., Mugnai, A., Panegrossi, G., and Sanò, P.: Transitioning from CRD to CDRD in Bayesian retrieval of rainfall from satellite passive microwave measurements: Part 3 -Identification of optimal meteorological tags, Nat. Hazards Earth Syst. Sci., 13, 1185-1208, doi:10.5194/nhess-13-11852013, 2013.

Sorooshian, S., Hsu, K.-L., Gao, X., Gupta, H. V., Imam, B., and Braithwaite, D.: Evaluation of PERSIANN system satellite- based estimates of tropical rainfall, B. Am. Meteorol. Soc., 81, 2035-2046, 2000.

Staelin, D. H. and Chen, F. W.: Precipitation observations near 54 and $183 \mathrm{GHz}$ using the NOAA-15 satellite, IEEE T. Geosci. Remote, 38, 2322-2332, 2000.

Staelin, D. H. and Surussavadee, C.: Precipitation retrieval accuracies for geo-microwave sounders, IEEE T. Geosci. Remote, 45, 3150-3159, 2007.

Staelin, D. H., Chen, F. W., and Fuentes, A.: Precipitation measurements using 183-GHz AMSU satellite observations, Geoscience and Remote Sensing Symposium 1999, IGARSS '99 Proceedings. IEEE 1999 International, 4, 2069-2071, 1999.

Stephens, G. L. and Kummerow, C. D.: The remote sensing of clouds and precipitation from space: a review, J. Atmos. Sci., 64, 3742-3765, 2007.

Surussavadee, C. and Staelin, D. H.: Millimeter-wave precipitation retrievals and observed-vs.-simulated radiance distributions: sensitivity to assumptions, J. Atmos. Sci., 64, 3808-3826, 2007.

Surussavadee, C. and Staelin, D. H.: Global millimeter-wave precipitation retrievals trained with a cloud-resolving numerical weather prediction model, Part I: Retrieval design, IEEE T. Geosci. Remote, 46, 99-108, 2008a.

Surussavadee, C. and Staelin, D. H.: Global millimeter-wave precipitation retrievals trained with a cloud-resolving numerical weather prediction model, Part II: Performance evaluation, IEEE T. Geosci. Remote, 46, 109-118, 2008 b.

Surussavadee, C. and Staelin, D. H.: Satellite Retrievals of Artic and Equatorial Rain and Snowfall Rates Using Millimeter Wavelengths, IEEE Trans. Geosci. Remote Sens., 47, 3697-3707, 2009.

Surussavadee, C. and Staelin, D. H.: Global precipitation retrievals using the NOAA AMSU millimeter-wave channels: comparisons with rain gauges, J. Appl. Meteorol. Climatol., 49, 124-135, 2010.

Surussavadee, C., Blackwell, W. J., Entekhabi, D., and Leslie, R. V.: A global precipitation retrieval algorithm for SUOMI NPP ATMS, IGARSS 2012, IEEE International Geoscience and Remote Sensing Symposium, doi:10.1109/IGARSS.2012.6351128, Munich, 2012.

Tripoli, G. J.: A nonhydrostatic mesoscale model designed to simulate scale interaction, Mon. Weather Rev., 120, 1342-1359, 1992.

Tripoli, G. J. and Smith, E. A.: Introducing Variable-Step Topography (VST) coordinates within dynamically constrained Nonhydrostatic Modeling Systems (NMW), part 1: VST formulation within NMS host model framework, Dynam. Atmos. Oceans, 66, 28-57, doi:10.1016/j.dynatmoce.2014.01.001, 2014a.

Tripoli, G. J. and Smith, E. A.: Introducing Variable-Step Topography (VST) coordinates within dynamically constrained Nonhydrostatic Modeling Systems (NMW), part 2: VST performance on orthodox obstacle flows, Dynam. Atmos. Oceans, 66, 10-27, doi:10.1016/j.dynatmoce.2014.01.003, 2014b.

Wang, J. R., Wilheit, T. T., and Chang, L. A.: Retrieval of total precipitable water using radiometric measurements near 92 and 183 GHz, J. Appl. Meteorol., 28, 146-154, 1989.

Wang, J. R., Zhan, J., and Racette, P.: Storm-associated microwave radiometric signatures in the frequency range of $90-220 \mathrm{GHz}, \mathrm{J}$. Atmos. Ocean. Tech., 14, 13-31, 1997. 
Weng, F. and Grody, N. C.: Retrieval of ice cloud parameters using a microwave imaging radiometer, J. Atmos. Sci., 57, 1069-1081, 2000.

Weng, F., Zhao, L., Ferraro, R. R., Poe, G., Li, X., and Grody, N. C.: Advanced microwave sounding unit cloud and precipitation algorithms, Radio Sci., 38, 8068-8079, 2003.

Wilheit, T., Adler, R., Avery, S., Barret, E., Bauer, P., Berg, W., Chang, A., Ferriday, J., Grody, N., Goodman, S., Kidd, C., Kniveton, D., Kummerow, C., Mugnai, A., Olson, W., Petty, G., Shibata, A., and Smith, E.: Algorithms for the retrieval of rainfall from passive microwave measurements, Remote Sensing Rev., 11, 163-194, 1994.
Wilks, D. S.: Statistical methods in the atmospheric sciences: an introduction, Academic Press, ISBN: 0-12-751965-3, 1995.

Young, G. S.: Implementing a neural network emulation of a satellite retrieval algorithm, in: Artificial Intelligence Methods in the Environmental Science, edited by: Haupt, S. E., Pasini, A., and Marzban C., Springer, 207-216, 2009.

Zhao, L. and Weng, F.: Retrieval of ice cloud parameters using the advanced microwave sounding unit, J. Appl. Meteorol., 41, 384 395, 2002. 